University of Massachusetts Amherst

ScholarWorks@UMass Amherst

Masters Theses

Dissertations and Theses

July 2019

\title{
Dysphagia Management in Schools: A Survey of Speech- Language Pathologists
}

Catherine Felicetti

University of Massachusetts Amherst

Follow this and additional works at: https://scholarworks.umass.edu/masters_theses_2

Part of the Rehabilitation and Therapy Commons, and the Special Education and Teaching Commons

\section{Recommended Citation}

Felicetti, Catherine, "Dysphagia Management in Schools: A Survey of Speech-Language Pathologists" (2019). Masters Theses. 771.

https://doi.org/10.7275/14182568 https://scholarworks.umass.edu/masters_theses_2/771

This Open Access Thesis is brought to you for free and open access by the Dissertations and Theses at ScholarWorks@UMass Amherst. It has been accepted for inclusion in Masters Theses by an authorized administrator of ScholarWorks@UMass Amherst. For more information, please contact scholarworks@library.umass.edu. 
Dysphagia management in schools: A survey of speech-language pathologists

A Thesis Presented

By

CATHERINE FELICETTI

Submitted to the Graduate School of the

University of Massachusetts Amherst in partial fulfillment

of the requirements for the degree of

\section{MASTER OF ARTS}

May 2019

Communication Disorders 
Dysphagia management in schools: A survey of speech-language pathologists

A Thesis Presented

by

CATHERINE FELICETTI

Approved as to style and content by:

Kelly Richardson, Committee Chair

Angela Mansolillo, Committee Member

Karen Helfer, Department Chair

Communication Disorders 


\section{ACKNOWLEDGEMENTS}

First, I would like to thank my thesis advisors, Kelly Richardson, Ph.D., CCCSLP and Angela Mansolillo, M.A., CCC-SLP, BCS-S. I could not have completed this project without their guidance and expertise. I would also like to thank the faculty and staff in the University of Massachusetts Amherst Communication Disorders program and my family for their unwavering support these past two years. 


\begin{abstract}
DYSPHAGIA MANAGEMENT IN SCHOOLS: A SURVEY OF SPEECHLANGUAGE PATHOLOGISTS
\end{abstract}

MAY 2019

\title{
CATHERINE FELICETTI, B.S., ITHACA COLLEGE M.A., UNIVERSITY OF MASSACHUSETTS AMHERST
}

Directed by: Professor Kelly Richardson

Introduction: To date, few research studies have evaluated pediatric feeding and swallowing practices in school systems across the United States. This study aims to i) understand the factors that impact a speech-language pathologists (SLPs) level of comfort in providing these services, ii) to identify barriers to service provision, iii) develop a concrete understanding of a SLPs role in providing feeding and swallowing services in a school setting, and iv) to identify the types of service suggested by school-based SLPs in response to a fictional case study.

Methods: School-based SLPs and clinical fellows were invited to participate in a 10-15 minute web-based survey. The survey questions focused on basic demographic information, vocational history, barriers to treatment, and clinician comfort level. In addition, survey respondents were asked to develop a treatment plan in response to a fictional case study. In total, 200 anonymous survey responses were collected and analyzed.

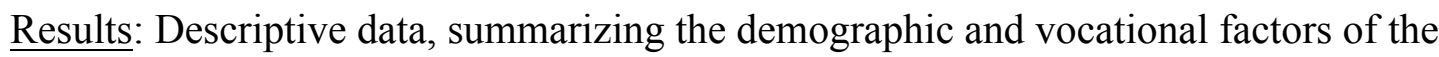
survey respondents, are provided. In addition, independent Pearson Chi-Square analyses were performed to determine the degree of association between the 
demographic/vocational factors and the SLPs self-reported comfort level. The results of these correlation analyses are reported and discussed. Barriers to dysphagia management and a summary of the services currently provided in the school setting are discussed from the perspective of professional practice issues. Analysis of the case study results indicated a wide range of treatment plans. The most common type of direct intervention suggested was an oral motor exercise regime, followed by diet modifications and the implementation of safe swallow strategies.

Discussion: The survey results indicate a number of factors impact clinician comfort level including geographic region, previous medical experience and current service provision. A number of barriers to practice were identified which include academic and/or clinical preparedness and concerns related to the educational relevance of service. Approximately $26.5 \%$ of survey respondents indicated that there were providing feeding and swallowing related services in a school setting with $98.1 \%$ of these clinicians providing collaborative consultation. The case study results highlighted the variability in treatment approaches. 


\section{TABLE OF CONTENTS}

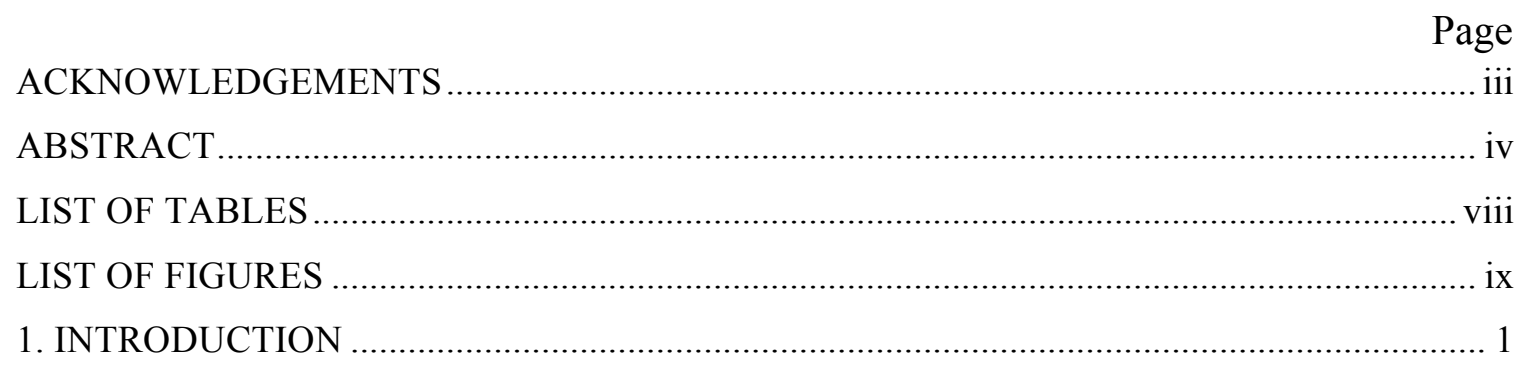

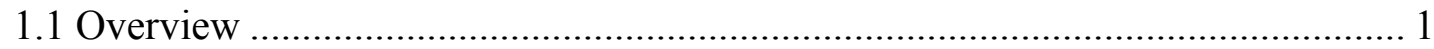

1.2 Typical Feeding and Swallowing Development........................................... 1

1.3 Disordered Feeding and Swallowing ............................................................. 3

1.4 Current Dysphagia Management Practices in the School Setting ....................... 6

1.4.1 Level 1: Collaborative Consultation ...................................................... 9

1.4.2 Level 2: Direct Therapeutic Intervention............................................... 10

1.4.3 Level 3: Intervention with Medically Fragile Students ............................. 11

1.4.4 Level 4: Transitioning to/from Tube Feeding ........................................... 11

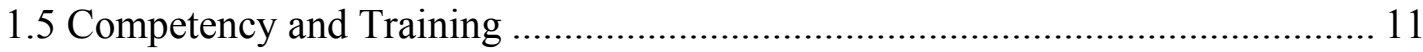

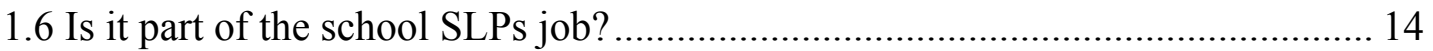

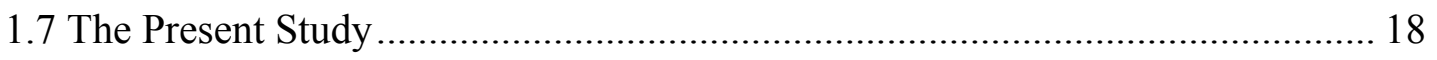

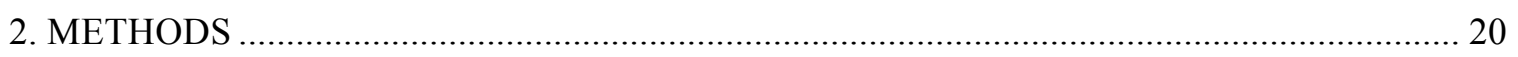

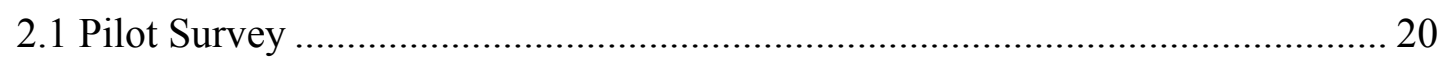

2.2 Participants and Survey Administration ................................................... 21

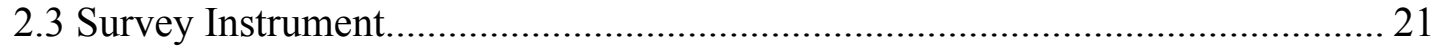

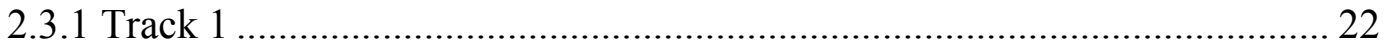

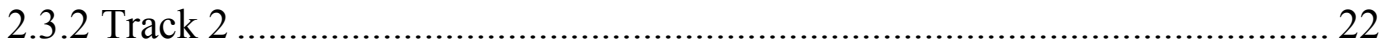

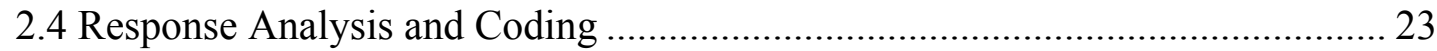

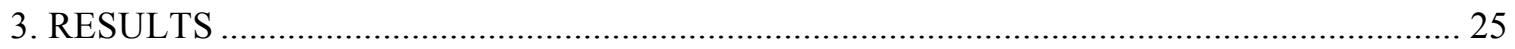

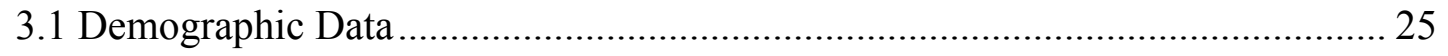

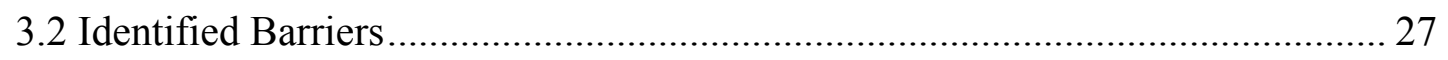

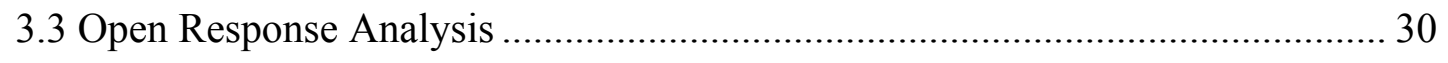

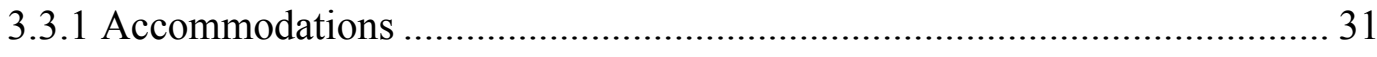

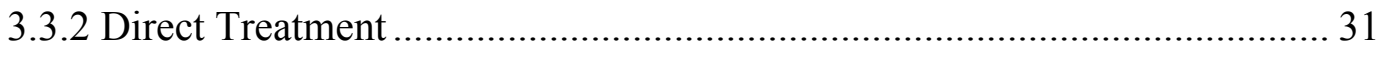

3.3.3 Follow Protocol Set Forth by Another Professional .................................. 33

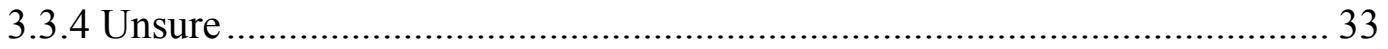


3.3.5 Refuse Treatment or Refer to an Outside Professional............................... 33

3.3.6 Variables Affecting Open Response Direct Treatment Plans ...................... 34

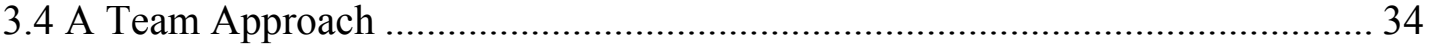

3.5 Status of Services Currently Being Provided ..................................................... 34

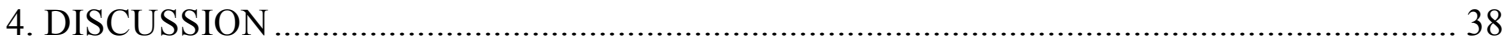

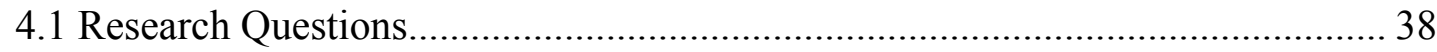

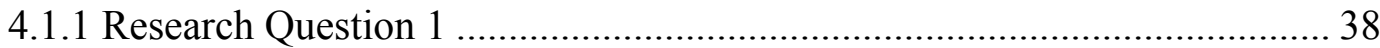

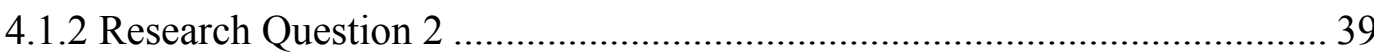

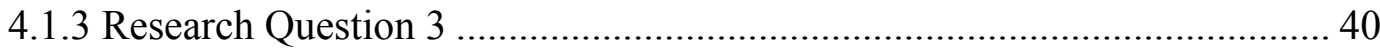

4.1.4 Research Question 4 ......................................................................... 45

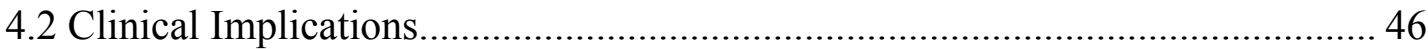

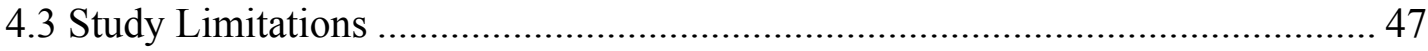

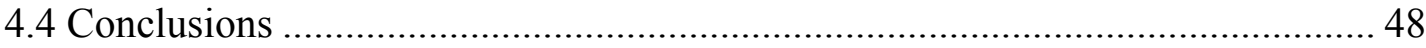

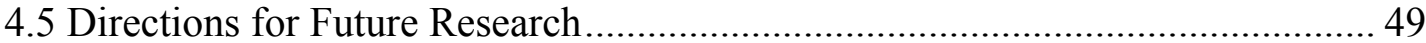

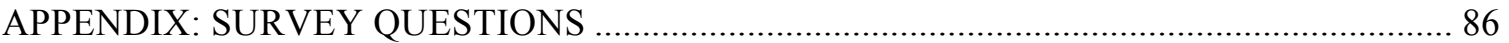

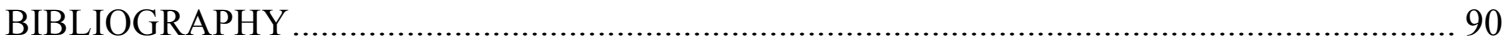




\section{LIST OF TABLES}

Table

Table 1. General Codes and Descriptions for NVivo 50

Table 2. Analysis of 17 Participants Who Indicated Accommodation Plans. 51

Table 3. Analysis of 77 Participants Who Indicated Direct Treatment Plans. 52

Table 4. Current School-based Service Provision. 56

Table 5. Pediatric Dysphagia Graduate School Training 57

Table 6. Years of Experience by Setting. 58

Table 7. Comfort Level Providing Feeding and Swallowing Services in School Setting. Number of Respondents Shown Across a 5-Point Likert Scale. 59

Table 8. Results of Correlation Analysis. 60

Table 9. Themes in Identified Barriers. 61

Table 10. Significant Demographic Variables for Differences in Identified Barrier Patterns.

Table 11. Significance of Variables Affecting the Provision of Direct Treatment in Open Response Answers 63

Table 12. Feeding and Swallowing Services Currently Provided by SLP in School Setting $(\mathrm{n}=52$ respondents). 64

Table 13. District Supports for Feeding and Swallowing Services in School Setting $(n=52$ respondents). 65

Table 14. Professional Knowledge Supplementation ( $\mathrm{n}=52$ respondents). 66 


\section{LIST OF FIGURES}

Figure

Page

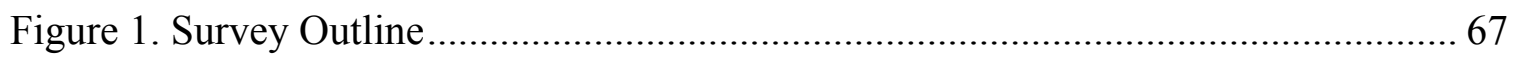

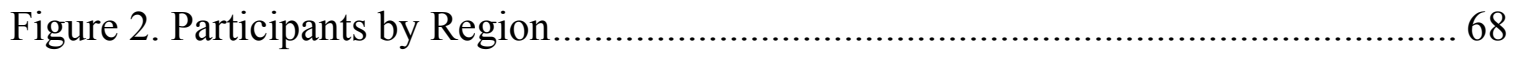

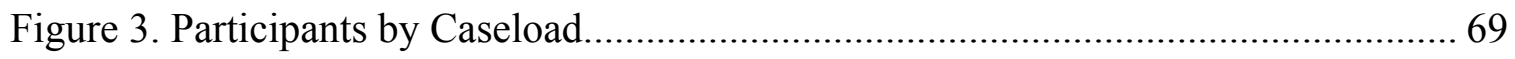

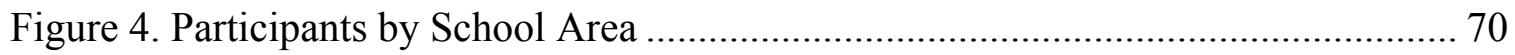

Figure 5. Participants by School Type ............................................................. 71

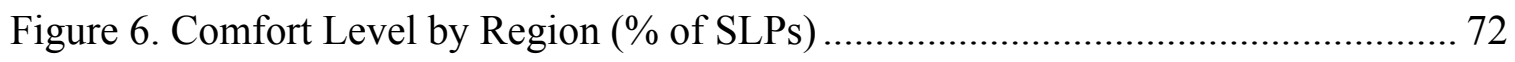

Figure 7. Comfort Level by Previous Medical Experience (\% of SLPs)........................ 73

Figure 8. Comfort Level by Service Provision (\% of SLPs) ...................................... 74

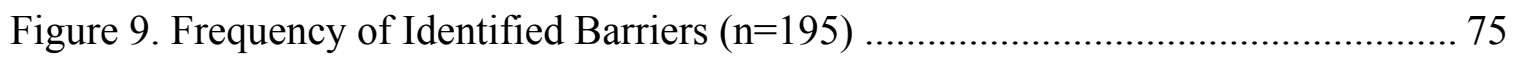

Figure 10. Caseload by Region (\% of SLPs by Caseload) ....................................... 76

Figure 11. Caseload by Past Medical Experience (\% of SLPs by Caseload) .................. 77

Figure 12. Caseload by Current Provision of Services (\% of SLPs) ............................. 78

Figure 13. Identified Barriers in Participants with High Caseloads $(n=52)$................... 79

Figure 14. Provision of Direct Treatment by Region (\% of SLPs) ............................... 80

Figure 15. Provision of Direct Treatment by Prior Medical Experience (\% of SLPs) ..... 81

Figure 16. Provision of Direct Treatment by Service Provision ( $\%$ of SLPs) ................. 82

Figure 17. Provision of Direct Treatment by Comfort Level (\% of SLPs)..................... 83

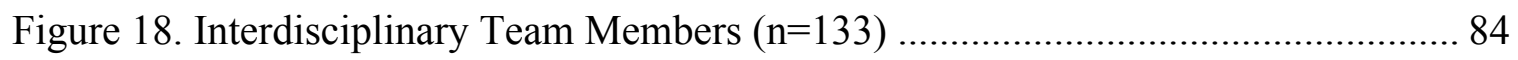

Figure 19. Students Receiving Outside Feeding and Swallowing Services .................. 85 


\section{CHAPTER 1 \\ INTRODUCTION}

\subsection{Overview}

The American Speech-Language and Hearing Association (ASHA) defines a speech-language pathologist (SLP) as a qualified individual who engages in professional practice in the areas of communication and swallowing across the life span (ASHA Scope, 2016). The roles and responsibilities of an SLP include the provision of service in the areas of fluency, language, speech production, cognition, voice, resonance, auditory rehabilitation, and feeding and swallowing.

As autonomous professionals, SLPs independently screen, assess, and treat communication and swallowing impairments associated with a variety of etiologies. In the feeding and swallowing domain, the provision of service includes assessing the anatomical structures and physiologic mechanisms which support the oral and pharyngeal stages of swallowing, as well as managing atypical eating patterns, including food refusal and food selectivity. While feeding and swallowing disorders can affect individuals across the lifespan this paper focuses on school-aged children with feeding and swallowing disorders.

\subsection{Typical Feeding and Swallowing Development}

Before delving deeper into the feeding and swallowing disorders that an SLP may encounter in working with the pediatric population, it is important to first establish a framework for a child's typical feeding and swallowing patterns. Swallowing is a complex process that involves the precise temporal coordination of oral and pharyngeal structures, with respiratory and sensorimotor processes. Research has shown that the integration of these systems begins during embryonic development and continues after 
birth (Stevenson \& Allaire, 1991). As a child grows, these reflexive responses either diminish or evolve into volitional behaviors. For example, a typically developing infant reflexively suckles in order to obtain adequate nutrition and hydration from his/her mother's breast or bottle (Delaney \& Arvedson, 2008). This reflexive suckling pattern, however, evolves into a more complex sucking motor pattern which is under the infant's volitional control.

The process of deglutition, or swallowing, can be divided into three overlapping sequential phases: the oral phase, pharyngeal phase, and esophageal phase (Stevenson \& Allaire, 1991). The oral phase of swallow, which is under volitional control, begins once food or liquid is introduced into the oral cavity. A cohesive bolus is formed by mixing the food or liquid with saliva which is subsequently transported to the oropharynx through lingual propulsion. Sensory receptors are triggered which elicits the non-volitional pharyngeal stage of swallow.

During the pharyngeal phase of swallow, the bolus is transported through the pharynx to the esophagus through gravity-assist and muscular peristalsis (Goyal \& Mashimo, 2006; Matsuo \& Palmer, 2008). As the bolus passes through the area of the hypopharynx, an airway protection response is observed. As the head of the bolus reaches the esophagus, a combination of cricopharyngeal muscle relaxation, increased pharyngeal pressure, and hyolaryngeal elevation allow the upper esophageal sphincter to open easily to allow the bolus to enter the cervical esophagus. This marks the end of the pharyngeal stage of swallow and the beginning of the esophageal stage. While SLPs may perform a screening of esophageal function during an instrumental swallow assessment, it is not in their scope of practice to diagnose or treat esophageal phase difficulties. 
As the anatomic structures of the oral cavity continue to grow and the child's oral motor patterns become more refined, children progress from consumption of liquids to softer and more complex textures (Goyal \& Mashimo, 2006). Around 6-9 months of age, infants are transitioned from soft foods and purees to more varied food textures. Textured purees (e.g. mashed banana, avocado), ground solids, and dissolvable solids (e.g. soft crackers or puffs) are gradually introduced as independent movement of the oral structures supports volitional mastication. Soft solids (soft fruits and vegetables) are introduced from 9-12 months of age and table foods begin being introduced around one year of age (Delaney \& Arvedson, 2008). With each increase in texture difficulty, we elicit more complex sensorimotor skills.

\subsection{Disordered Feeding and Swallowing}

The anatomic proximity of the esophagus and the trachea can pose a risk for aspiration or penetration of the bolus material. In aspiration, the bolus passes below the level of the true vocal folds and moves into the trachea. During penetration, the bolus enters the laryngeal vestibule, but it does not go below the level of the true vocal folds. With a strong reflexive cough, an individual can expel the foreign material from the entrance to the airway. Aspiration can lead to serious health consequences including chronic aspiration pneumonia, frequent choking and coughing episodes, and chronic breathing difficulties. It can also result in malnutrition if a child is not ingesting the amount or types of food they need to grow (Loughlin, 1989).

The list of pediatric feeding and swallowing disorders is extensive. Feeding disorders are characterized by a child restricting or avoiding food intake, displaying inappropriate mealtime behaviors, failing to master self-feeding skills for his/her 
developmental level, and/or experiencing less than optimal growth (Arvedson, 2008). A swallowing disorder, known as dysphagia, occurs during one or more of the three previously defined swallowing stages. For example, a child with pharyngeal stage dysphagia may aspirate food, liquid, saliva, and/or medication. A child with an oral stage dysphagia may exhibit difficulty with posterior propulsion of the bolus, or he/she may have difficulty positioning the bolus on his/her molars for an age-appropriate rotary chew pattern. Feeding and swallowing disorders can co-occur or occur independently of one another (Arvedson, 2008).

It is estimated that approximately $0.9 \%$ of children ages $3-17$ year have a diagnosed swallowing impairment (Bhattacharyya, 2015). The prevalence varies greatly however, among disordered populations. Prevalence is estimated to be around $80 \%$ for children with developmental disorders and children with autism are thought to be five times more likely to have a feeding disorder in comparison to their neuro-typical peers (Manikam, 2000; Sharp et al., 2013). Underlying etiologies of feeding and swallowing disorders vary greatly and may include developmental disabilities, genetic syndromes, medication side effects, neurological disorders, sensory integration issues, structural abnormalities, behavioral factors, and socio-emotional factors. Additionally, while feeding disorders are often considered in the context of an organic etiology, atypical feeding difficulties can also be examined on a continuum of psychosocial and organic factors (Manikam, 2000). As a result, feeding and swallowing impairment is best treated by a team of multidisciplinary professionals.

If left untreated, the long-term consequences of feeding and swallowing disorders can include food aversion, undernutrition, dehydration, ongoing need for supplemental 
nutrition, and psychosocial effects on the child. For a child who has reached school-age, a feeding and swallowing disorder is likely to cause disruptions to his/her school day. In order for school-aged children to access the curriculum efficiently and be able to participate in academic activities throughout the day, they require adequate nutrition and hydration. Children who do not eat or drink throughout the day can lack the stamina they need to focus during class, resulting in poor academic performance. Additionally, children who suffer from undernutrition, dehydration, aspiration, and pneumonia miss classes more often than their typical peers (Homer, 2015).

Manikam (2000) also notes the impact of feeding and swallowing disorders on the family unit, particularly the child's caregivers. Family routines can be difficult for families who have children with feeding and swallowing difficulties. Specifically, mealtimes can be significantly more difficult as the caregivers are responsible for ensuring their child's safety and nutrition (Angell, Bailey, Nicholson \& Stoner, 2009). Since eating often takes place at home, families play an integral role in helping children overcome feeding and swallowing difficulties. Families need to be aware of the effect feeding and swallowing disorders can have on a child's overall health and nutrition. Therefore, successfully treating feeding disorders requires extensive family education. This level of familial involvement can be stressful and overwhelming at times (Manikam, 2000; McNeilly \& Sheppard, 2008).

Schools are not only expected to educate students in the core curriculum, but to also facilitate their social and emotional growth. According to Durlak and colleagues (2011), schools are expected to produce emotionally intelligent students who are able to work with others and behave appropriately in social contexts (Durlak, Weissberg, 
Dymnicki, Taylor, \& Schellinger, 2011). Aspects of a child's social and emotional development undoubtedly occur during unstructured lunch and snack times during the school day. It can be one of the most natural contexts for students to observe appropriate social interaction and behaviors (Heyne, Wilkins, \& Anderson, 2012). According to the American Occupational Therapy Association (AOTA), mealtimes are an opportunity for students to learn age-appropriate behaviors like chewing with their mouth closed and to learn appropriate mealtime routines, including cleaning up after finishing one's meal. Mealtimes can also serve as important opportunities for social skill modeling such as listening, conversational turn-taking, topic introduction, and conversational volume. According to the AOTA, when a child is able to fully participate in lunch, it can help prevent social exclusion and bullying. They are more likely to feel connected to their school and their peers (AOTA, 2013).

\subsection{Current Dysphagia Management Practices in the School Setting}

Arvedson and Homer (2006) state that "no one discipline can, nor should, manage children with issues surrounding their feeding and swallowing." Instead, they present the concept of an interdisciplinary team consisting of the following professionals: caregivers, speech-language pathologist, occupational therapist, physical therapist, nurse, classroom teacher, dietitian, paraprofessional, and others involved in the care of these medically complex children (Arvedson \& Homer, 2006; Homer, Bickerton, Hill, Parham, \& Taylor, 2000). Within this interdisciplinary group, SLPs are the only professionals who complete specific coursework on dysphagia (Arvedson \& Homer, 2006). For this reason, Homer (2003) states that the SLP should be the "point person" for children with feeding and swallowing difficulties. The "point person," or the case manager, is responsible for 
coordinating services, ensuring appropriate procedures are followed, ensuring documentation is completed, and notifying all team members when changes to protocol are made (Homer, 2003). However, not all graduate school programs offer coursework in the area of pediatric dysphagia. SLPs often have to seek out readings, continuing education courses, or mentorship to continue learning about the topic (Arvedson \& Homer, 2006).

While interdisciplinary teams are presented in the literature as the gold standard for feeding and swallowing intervention, it appears that few schools have assembled such a team. In a large-scale Virginia-area study conducted in 2008 , only $7.2 \%(n=16 / 222)$ of speech language pathologists surveyed indicated that their school had a dysphagia team (O’Donoghue \& Dean-Claytor, 2008). A Vermont-based study of 52 ASHA-certified SLPs also reported a lack of support and infrastructure for feeding and swallowing management in the school system. Fewer than $5 \%$ of the survey respondents agreed that there were dysphagia intervention procedures, protocols, and guidelines in place to support SLPs providing services (Hutchins, Gerety, \& Mulligana, 2011). Fewer than 15\% of survey respondents agreed that their administrators and colleagues would provide a high level of support in their efforts to provide dysphagia services (Hutchins et al., 2011). The survey instrument did not identify the perceived barriers to service provision.

Children with feeding and swallowing disorders are often medically complex and/or fragile. As a result, the proposed school-based interdisciplinary team must communicate with the child's doctors and other health care professionals involved in the child's plan of care (Arvedson \& Homer, 2006). Interdisciplinary conferences can take a significant amount of time, which is a finite resource that school-based SLPs are not 
always afforded. Hutchins and colleagues (2011) reported that SLPs widely agreed that there would be logistical and scheduling issues with providing feeding and swallowing services in the school system. The barriers to providing feeding and swallowing services in the school system, however, remain unclear and will be addressed in the present study.

Owre (2001) states that there are a wide variety of feeding and swallowing service models in school systems across the United States. These models vary from heavily involved treatment, to no treatment at all. In order to successfully implement a feeding and swallowing program in a school system, Homer (2008) outlines several points of information that need to be addressed. School systems need to identify the suspected prevalence of feeding and swallowing difficulties, assess the current safety status of their students, identify expenses, and then design a plan. Under "identifying expenses", Homer (2008) stated that school districts should take into account personnel expenses, as well as the estimated costs of training.

Cost is frequently identified as a barrier to providing special education services. It is estimated to cost 1.6 to 3.1 times the amount of money to educate a child who requires special education services, in contrast to their typically developing peers (Power deFur, \&Alley, 2008). In order to help mitigate this financial strain on school districts, IDEA mandated that schools be able to bill for Medicaid-eligible students. Since children with feeding and swallowing disorders typically have complex medical needs, they are often eligible for Medicaid (Power deFur \& Alley, 2008; Lefton-Greif \& Arvedson, 2008). While Medicaid is typically the "payer of last resort," school districts may bill Medicaid as the primary source of funding, prior to taxing the limited and likely already strained financial resources of their school district. 
Homer (2015) outlines four levels of feeding and swallowing services that could reasonably be provided in a school setting: collaborative consultation, direct therapeutic intervention, intervention with medically fragile students, and transitioning to/from tube feeding (Homer, 2015). These four service categories are further defined and discussed below.

\subsubsection{Level 1: Collaborative Consultation}

Collaborative consultation involves gathering and sharing information regarding the child's feeding and swallowing plan, coordinating team member's efforts, and resolving issues as they come up. For example, when a new child enters the school system, the SLP would monitor the child and determine the most effective course of action. They would then instruct the team members on mealtime presentation, environment (e.g. reduced distractions), and positioning. With the help of an occupational therapist, assistive or adaptive seating may be deemed helpful during mealtimes to help the child sit upright with their feet firmly planted, better facilitating a typical swallow pattern (Bailey \& Angell, 2008).

As the child moves schools and ages, this plan and the recommendations may need to be reassessed, which could be done through a similar consultative model executed by the SLP. For this reason, monitoring is considered part of collaborative consultation. The child will need consistent and ongoing monitoring. Homer (2015) states that monitoring occurs while a child is eating. The SLP can look at the child's behaviors, if strategies are being implemented, and the effectiveness of the implemented plan. It is then the SLPs responsibility to share this information with the child's team and suggest 
changes as necessary (Homer, 2015). Within a district of Louisiana-based SLPs, monitoring was found to be the most common type of intervention (Homer, 2008).

\subsubsection{Level 2: Direct Therapeutic Intervention}

According to Homer (2015), Level 2 is working with the child directly during therapeutic sessions to target feeding and swallowing goals. This level includes gathering baseline data about the child's needs and abilities, documenting a planned treatment approach, implementing the treatment approach, and then continuously evaluating the effectiveness of the treatment approach. The SLP will need to make changes to the treatment plan as necessary.

There is a limited evidence base for pediatric feeding and swallowing treatments. In a literature review of treatment methods for children with oral-pharyngeal stage dysphagia, Morgan and colleagues assessed both strength-based exercises and oral sensori-motor methods of treatment (Morgan, Dodrill, \& Ward 2012). The authors concluded that there is not currently enough evidence to validate either approach and stated that additional large-scale studies need to be conducted (Morgan et al., 2012). Homer (2015) cautions that feeding and swallowing treatment will need to be childspecific and combine evidence-based research with clinical judgment.

Part of direct therapeutic intervention is also connecting with the child's caregivers to ensure the strategies used at school have effective carryover to home mealtimes (Angell et al., 2009). As discussed earlier, the success of pediatric feeding and swallowing treatment often relies on the involvement of caregivers as part of the therapeutic team. This requires extensive caregiver training and ongoing communication 
with families. Most families do not view the annual IEP meeting as enough feedback for issues related to feeding and swallowing.

\subsubsection{Level 3: Intervention with Medically Fragile Students}

The presence of a feeding or swallowing disorder is commonly associated with preterm births, children with respiratory conditions, and children with neurological conditions. These children are considered medically complex and are at a higher risk than their typically developing peers for subsequent problems related to feeding and swallowing. As an increasing number of these children are born, survive infancy, and enter mainstream schools, the demand for feeding and swallowing services is expected to rise (Lefton- Greif \& Arvedson, 2008). Depending on the nature and extent of the child's medical condition, intervention may involve ongoing monitoring to assess changes to the child's feeding and swallowing safety at school and the development of an emergency plan that all members of the child's school team will be educated on.

\subsubsection{Level 4: Transitioning to/from Tube Feeding}

This level of treatment involves working with children who have received, are receiving, or are weaning from nasogastric tubes, gastronomy tubes, or jejunostomy tubes (Homer, 2015). School-based dysphagia teams work closely with the child's primary care physician, the medical team, and the child's caregiver(s) to make the transition at school smooth. This is considered the most involved level of feeding and swallowing support. When given a child with non-enteral feeding needs, the SLP would typically be involved on all three of the prior levels of care through staff education, monitoring and consulting, the creation of a safety plan, and therapeutic feedings if appropriate (Homer, 2015).

\subsection{Competency and Training}


Competency and training levels are the most frequently cited reason as to why school-based SLPs are uncomfortable providing feeding and swallowing services within the school system (O'Donoghue \& Dean-Claytor, 2008). In the Virginia-area study, there was a significant and positive correlation between the number of continuing education units taken and the school-based SLPs comfort level with evaluating and implementing treatment for feeding and swallowing difficulties (O'Donoghue \& Dean-Claytor, 2008). It was further noted that the recency of the continuing education units (units taken within the last 2 years) was significantly and positively correlated with the SLPs confidence in treating feeding and swallowing impairment in the school setting (O'Donoghue \& DeanClaytor, 2008).

These findings were further supported by the Vermont-based study of schoolbased SLPs and a Midwest-based study of school-based SLPs (Hutchins et al., 2011; Bailey, Stoner, Angell \& Fetzer, 2008). While all survey respondents largely agreed that the SLPs job is to provide feeding and swallowing services in the school system, they reported that they were uncomfortable providing such services due to a lack of essential training. The researchers found that the survey data were consistent with previous qualitative and quantitative survey results (Hutchins et al., 2011, Bailey, et al., 2008).

Hutchins and colleagues (2011) further identified a significant and positive correlation between SLPs who had worked in the medical field prior to working in an educational setting and their self-identified comfort levels. SLPs with prior medical experience were seemingly more confident in treating feeding and swallowing in the school system (Hutchins et al., 2011). This was consistent with Bailey et al. (2008) who reported that school-based SLPs, who did not have prior medical experience setting, were 
more likely to point out their lack of hands-on experience. This information aligns with the 2017 ASHA Healthcare Survey and the 2018 ASHA Schools Survey. In a pediatric hospital setting, over $30 \%$ of an SLPs caseload is based in feeding and swallowing services. In most adult medical settings, over 50\% of an SLPs caseload is expected to be providing feeding and swallowing services (ASHA Healthcare, 2017). In a school setting, only $10.5 \%$ of SLPs work with children who have feeding and swallowing needs. Their caseload percentage is not specified (ASHA Schools, 2018). Therefore, it is likely that SLPs practicing in a medical setting have had a greater amount of hands-on training and experience with feeding and swallowing impairments, something SLPs feel is lacking from the school-based environment (O'Donoghue \& Dean-Claytor, 2008).

Carnaby and Harenberg (2013) distributed an online survey to medically-based SLPs in order to assess their methodology for treating feeding and swallowing disorders. The survey contained a video-supported, fictional case study. In total, 254 survey participants respond to questions about treatment. Over $91 \%$ of survey respondents agreed that treatment was warranted for the patient. However, there were few similarities across proposed treatment plans. Over 96 therapy combinations were indicated that integrated 47 different well-known therapy techniques. No therapy combination was repeated across participants. Additionally, over $58 \%$ of the techniques discussed did not correspond to the fictional case-study symptoms when compared with evidence-based practice. The variance of results suggests the need for more systematic treatment methodology in dysphagia management (Carnaby \& Harenberg, 2013). This study shows that even in a medical setting, where SLPs are likely to be more comfortable with treating feeding and swallowing difficulties on a day to day basis, there appears to be no steadfast 
protocols to follow. This could make it more difficult for school-based SLPs to integrate feeding and swallowing case management into their schedules. To the researcher's knowledge, no similar research study has been conducted with school-based SLPs to date.

\subsection{Is it part of the school SLPs job?}

School-based professionals are bound by several laws that affect educational rights in schools. The first law was enacted in 1975 when the Education for All Handicapped Children mandated that all public schools provide services to all children with severe disabilities. At this time, the law did not mandate how the districts should educate the children. Typically, they were educated in separate classrooms and had little to no contact with their typically-developing peers. This has changed drastically over the past 20 years. In 1997, the Education for All act was updated by the Individuals with Disabilities Act (IDEA). This law was updated again in 2004 and is now referred to as IDEA 2004. Part B of IDEA 2004 governs the educational rights of children ages 3 through 21 and their caregivers.

IDEA 2004 introduced the concept that students not only need to be educated by the public school system, but that they also have access to a free and appropriate public education (FAPE). FAPE guarantees that children will be educated at no cost to the child's caregivers and that they will ensure the education is appropriate, meaning that it is student specific. Under "appropriate" education, students are guaranteed to be educated in their least restrictive environment (LRE). The LRE differs for each child, but the law mandates that children are educated to the maximum extent possible with their typicallydeveloping peers (Kauffman, Hallahan, \& Pullen, 2017; Angell et al., 2009; Homer, 
2008). This suggests that if a student is consistently missing school to attend outside feeding therapy, if they are frequently sick due to aspiration pneumonia or malnutrition, or if they are unable to focus in class due to untreated feeding and swallowing difficulties, then it is unlikely the child is being educated in their LRE and therefore their education is not meeting the guidelines set forth by IDEA 2004. Furthermore, the concept of education does not only include a child's academic performance. As discussed earlier, the school is also expected to be facilitating a child's social and emotional development. Therefore, if a child is consistently being pulled out of lunch to eat in the nurse's office, rather than being provided with one-to-one lunchtime supervision in the cafeteria, this could also be considered not educating a student within their LRE.

It is often argued that children with feeding and swallowing disorders do not qualify for treatment under the law. IDEA 2004 outlines 13 categories of disability that are covered. One of the categories is broadly listed as "other health impaired." A child with a feeding and swallowing disorder could fall within this category if their difficulties are likely to impede their academic success. Additionally, many children with feeding and swallowing disabilities may already qualify under one of the twelve other categories like multiple disabilities, traumatic brain injury, or autism, as these frequently co-occur with feeding and swallowing disturbances (Arvedson \& Homer, 2006). Feeding and swallowing services may be appropriate to include under one of those preexisting qualifiers. Additionally, IDEA guarantees children the right to access "school health services." These health services can be provided by a school nurse or another "qualified person," like a speech language pathologist if they help a child benefit from their education (Angell et al., 2009). 
Not providing feeding and swallowing services can leave a school district vulnerable to legal difficulties. Past legal cases have exemplified this. For example, in New Mexico in 2003, courts ruled in favor of a child who needed a modified diet and strategic accommodations during mealtimes. The school was required to create a health plan and provide adequate staff training (New Mexico Department of Education 103 LRP, 57798, SEA NM 2003). In 2004, a New Hampshire school district was found liable for a child's two hospitalizations related to aspiration-pneumonia. The school district failed to comply with the child's diet modifications and they did not provide safety accommodations, placing the child at continued risk (Contoocock Valley School District, 41 IDELR 45, SEA NH 2004). The government has sided with caregivers on behalf of IDEA throughout history. In 2012, in Arkansas, a hearing concluded that it was vital schools provide detailed health and emergency plans for students, as appropriate (Benton School District, 113 LRP 17149, SEA AR 2012). School districts would benefit from having plans in place to effectively treat students with feeding and swallowing needs.

Connecticut and Virginia are the two states which have published guidelines through their Department of Education pertaining to the school-based SLPs role in providing feeding and swallowing services. In 2008, Connecticut published a manual specific for feeding and swallowing service provision in schools. The manual outlines the legality of providing services in schools, including information on HIPAA and how to communicate with healthcare providers. The sections address receiving feeding and swallowing referrals, determining eligibility, components of an evaluation, and implementing services in the schools with the appropriate team members. The manual 
includes information for SLPs, dietitians, occupational therapists, food service professionals, teachers, mental health staff, and more (Connecticut DOE, 2008).

The state of Virginia took a different approach to addressing the SLPs role in feeding and swallowing services in the school system. Within the general manual for SLPs in schools, Virginia included a section on dysphagia. The section outlines team members that the SLP should consult with, signs and symptoms to be aware of, and the need for an individualized health plan. There are no specific protocols outlined for referrals, evaluation, or treatment in the manual (VDOE, 2018). When implementing this new protocol, the state of Virginia recognized the need for additional training for schoolbased SLPs in the area of feeding and swallowing. They held eleven regional training sessions for school-based SLPs. The sessions were designed to target foundational knowledge of pediatric feeding and swallowing, clinical application, and a team management approach. The state of Virginia also provided their SLPs with an avenue for consultative support. Their department of education maintains a database of professionals with specialized skill sets, like pediatric feeding and swallowing. This database allows school-based professionals to request a remote or in person consultation (O'Donoghue \& Hegyi, 2009).

According to O'Donoghue and Hegyi (2009), this collaborative-consultation model makes providing feeding and swallowing services in schools more practical. It would not be reasonable to expect every SLP in a school district to be fully competent in providing pediatric feeding and swallowing services, as it would often be considered a low-incidence population. O'Donoghue and Hegyi (2009) states that typically, for each school district or region, there is one SLP considered to be the expert in providing these 
services. This person can serve as a consultant for other SLPs in the area, enabling more children to access efficient feeding and swallowing services.

ASHA (2007) published "Guidelines for Speech-Language Pathologists Providing Swallowing and Feeding Services in Schools". This statement was rescinded in 2014, moved to the ASHA archives, and is no longer available on the ASHA website. It was removed among other statements pertaining to feeding and swallowing disorders including "Speech-Language Pathologists Training and Supervising Other Professions in the Delivery of Services to Individuals with Swallowing and Feeding Disorders: Technical Report" and "Roles of Speech-Language Pathologists in Swallowing and Feeding Disorders: Position Statement, 2002.” ASHA now directs school-based professionals to the ASHA practice portal on Pediatric Dysphagia, however, this information is not specific to providing feeding and swallowing services in a school setting.

\subsection{The Present Study}

The purpose of the present study was to understand current school-based feeding and swallowing practices across the United States. Anonymous survey responses were obtained for SLPs and clinical fellows currently practicing in a school setting. The survey data allowed us to address the following research questions:

1. What demographic variables affect a school-based SLPs self-reported comfort level in providing feeding and swallowing services?

2. What do school-based SLPs view as barriers to providing effective feeding and swallowing services in the school system? 
3. What types of services would be suggested by school-based SLPs when presented with a student who has oral-pharyngeal stage dysphagia?

4. What is the status of feeding and swallowing services currently being provided in schools and how do schools support these services? 


\section{CHAPTER 2}

METHODS

In order to evaluate the usual practices of SLPs who manage feeding and swallowing impairment in a school-based setting, an internet-based questionnaire was administered from May 17, 2018 until November 1, 2018. A board-certified swallowing specialist was consulted to ensure the clinical relevancy of the fictional case study and all survey questions.

\subsection{Pilot Survey}

To eliminate survey bias and to help refine the survey questions, a pilot survey was distributed to school-based SLPs in the Amherst, Massachusetts area from May 4, 2018 to May 17, 2018. The SLPs who received the survey invitation were affiliated with the Center for Language, Speech, and Hearing at the University of Massachusetts Amherst. Survey participation was voluntary and anonymous and no incentives to participate were offered. In this pilot study, 85 school-based SLPs received the survey invitation with 6 SLPs completing the survey (7\% response rate). The survey responses were analyzed for comprehensibility using the software program NVivo (QSR International Ltd, 2014). The survey questions were found to be suitable. No questions were adapted for survey administration and all preliminary responses were included in the data analysis. The question order however, was adjusted in the final survey instrument. The open response section, related to the fictional case study, was moved to the end of the survey. This was done to increase the participant response rate. With this modification, the participants first completed the obligatory multiple choice and short answer sections. The open response section was not obligatory and participants could 
submit the survey without proceeding to the fictional case study. Participants who completed at least $70 \%$ of the survey were included in the final analysis. The survey instrument and all related study materials were approved by the Institutional Review Board at the University of Massachusetts Amherst.

\subsection{Participants and Survey Administration}

Following the pilot survey, participants were recruited from the American Speech-Language and Hearing Association's (ASHAs) community resource platform. Study information and a recruitment link were posted on ASHAs general community forum, Special Interest Group 13 (Swallowing and Swallowing Disorders- Dysphagia), and Special Interest Group 16 (School-based Issues). The survey was also posted on professional forums (e.g. Facebook groups). ASHA-certified SLPs and clinical fellows who were currently working in the school system were invited to participate in the survey. Participation was voluntary and no incentives to participate were offered. All survey responses were anonymous. In total, 216 participants completed the survey: 199 SLPs and 17 clinical fellows. Sixteen survey respondents were disqualified for failing to meet the $70 \%$ response criteria. In total, 200 responses were analyzed.

\subsection{Survey Instrument}

The online survey (Qualtrics, 2013) was designed to be completed in 15-20 minutes. The survey could only be completed once by each participant. To ensure the participants' responses were not influenced by subsequent questions, participants could not return to previously answered questions. All responses were anonymously recorded in Qualtrics (2013). The survey instrument is depicted in Figure 1. All survey questions are included in Appendix A. 
The survey was divided into three sections. The first section gathered demographic and vocational data from all participants using a series of short-answer and multiple choice questions.

The second section divided participants into two tracks based on their response to Question \#9: "Do you currently provide feeding and swallowing services within your school district?" Participants who indicated 'yes' were directed to Track 1: SLPs who are currently providing feeding and swallowing services in their school district. Participants who indicated 'no' were directed to Track 2: SLPs who are not currently providing feeding and swallowing services in their school district.

\subsubsection{Track 1}

Participants who indicated that they are currently providing feeding and swallowing services within their school district were asked a series of questions pertaining to financial and non-financial support they receive, interdisciplinary efforts, and ongoing professional education pertaining to the topic. They were also asked to characterize the nature and extent of services they were providing related to feeding and swallowing impairment.

\subsubsection{Track 2}

SLPs who indicated that they were not currently providing swallowing and feeding therapies responded to questions about students who may benefit from feeding and swallowing services in their district and to identify potential barriers to treatment.

The third section utilized an open response format where all survey participants were asked to respond to a fictional case study of a child presenting with oral-pharyngeal dysphagia of an undisclosed etiology. After reviewing the case history and the child's 
presenting symptoms, the SLPs were asked to create a plan of care. The SLPs were also asked to identify other professional who should be part of the interdisciplinary care team. 2.4 Response Analysis and Coding

Demographic and vocational data were exported from Qualtrics (Qualtrics, 2013) into Microsoft Excel (Version: 15.27, 2016). Descriptive statistics were computed for the following: number of SLP and clinical fellow respondents, degree of pediatric dysphagia coursework, number of participants by region, number of participants by school type, number of participants by school area, average years of experience per vocational setting, range of experience by vocational setting, number of participants by caseload, number of participants comfortable providing feeding and swallowing services, and number of participants who identified each barrier. Additional descriptive statistics, related to current provision of service, were computed for Track 1 participants. They were as follows: number of participants by type of service provision, number of participants receiving district support, and number of participants who supplement their knowledge of feeding and swallowing.

The open responses for the fictional case study were analyzed using a commercial software program, NVivo (QSR International Ltd, 2014). NVivo is a customizable software platform that supports qualitative data analysis (QSR International, 2014). Individual participant responses were first coded using the system outlined in Table 1. Each open response was coded using at least one general code. The general codes "Accommodations" and "Direct Intervention" were subsequently coded more refinely to capture the nuances in the participants' responses. This coding system is outlined in Table 2 (Accommodations) and Table 3 (Direct Intervention). 
IBM SPSS Statistics Software (Version 25, 2017) was utilized to determine the relationship between variables in the dataset. Independent Chi-Square analyses were performed to determine the relationship between variables. The following variables were used as a basis of comparison: self-identified comfort level, provision of direct treatment (open response), and patterns of barrier identification. The following demographic variables were used for comparison: pediatric dysphagia coursework, school region, school type, medical experience, SLP caseload, current service provision, and years of experience. A significance level of 0.05 was used for all statistical analyses. These analyses are discussed in Chapter 3. 


\section{CHAPTER 3}

RESULTS

\subsection{Demographic Data}

A total of 53 responses were collected from participants who are currently providing feeding and swallowing services within their school system (Table 4). The remaining 147 participants reported that they are not currently providing feeding and swallowing services in their school system (Table 4). Further demographic information obtained pertained to the clinicians certification status, graduate school training, years of experience by vocational setting, and comfort level providing feeding and swallowing services. These demographic variables are summarized in Tables 4-7, respectively.

As shown in Table 4, the majority of survey respondents were ASHA-certified SLPs $(91.5 \%)$ with the remainder being clinical fellows $(8.5 \%)$ working towards their ASHA certification.

In Table 5, graduate school training was considered to be any coursework in the area of pediatric dysphagia. This included: pediatric dysphagia covered as part of the ASHA required adult dysphagia course, a standalone pediatric dysphagia course, a one credit seminar, or a workshop. Some participants selected "other" and specified that pediatric dysphagia material was covered in another course (e.g. neurology or motor speech disorders). This was counted as being exposed to graduate school training in the area of pediatric feeding and swallowing. In total, 59.5\% of ASHA-certified SLPs and clinical fellows indicated that they received some level of graduate school training in the area of pediatric feeding and swallowing. Specifically, $7.6 \%$ of survey respondents had a standalone pediatric dysphagia course, $14.3 \%$ reported $25-50 \%$ pediatric content in the adult dysphagia course, $71.4 \%$ reported $0-25 \%$ pediatric content in adult dysphagia 
course; $4.2 \%$ had a pediatric dysphagia seminar, and 2.5\% indicated "other" (e.g. content embedded in other course).

All participants had experience in an educational setting as it was a requirement for participation in the study. The mean years of experience in an educational setting was 11.7 years $(S D=9.9)$. Medical inpatient was the second most popular setting to have worked in for a period of time. The mean years of experience in a medical inpatient setting was 4.1 years $(S D=4.9)$. The average years of experience across vocational settings is summarized in Table 6.

Participant comfort level providing services for feeding and swallowing disorders was considered demographic information. A 5-point Likert scale was used to assess clinician comfort level when providing services for feeding and swallowing disorders in a school setting. The participant's self-identified comfort levels are summarized in Table 7. Previous research has indicated that prior medical experience impacts a clinician's comfort level in providing feeding and swallowing services in a school setting (Hutchins et al., 2011; Bailey et al., 2008). However, no previous study has examined the impact of a broad array of variables on self-reported comfort level. The present study examined the impact of eight variables on clinician comfort level: pediatric dysphagia coursework, region, school type, school area, prior medical experience, caseload statistics, current service provision, and years of experience in a school setting. The results of the Pearson Chi Square analysis, shown in Table 8, indicate a significant correlation between the clinicians' self-reported comfort level and their geographic region, prior medical experience, and current service provision. The descriptive data for each of these 
demographic variables are displayed in Figures 6-8. No other correlations were found to be statistically significant (Table 8 ).

Additional demographic information pertaining to the participant's region, caseload, school area, and school type are summarized in Figures 2-5. As indicated by Figure 2, the majority of participants (58\%) were from the Northern region of the United States. Figure 3 outlines the average caseload statistics across survey respondents. As illustrated in Figures 4 and 5, the majority of respondents identified as practitioners in a public school (87\%) in a suburban area (48\%).

\subsection{Identified Barriers}

Participants were presented with a list of six service barriers (ethics, relevance, preparedness, time, finances, and administrative support), and they were asked to select which barriers they felt were most relevant. Participants were able to select multiple items. In total, 195 participants completed this question. The most frequently identified barriers are shown in Figure 9. The most commonly selected barrier was clinician preparedness to provide effective services (64.6\%), followed by the relevance of feeding and swallowing services in schools (57.4\%). Participants also had the opportunity to select "other" and specify additional barriers. Other barriers included: lack of caregiver support, limited referrals, difficulty communicating with family members, and difficulty ensuring effective follow through at home. The most popular "other" answer was communication difficulty between school-based professionals and the medical professionals the child sees.

Using the three variables (region, prior medical experience, and current service provision) that were significantly correlated with clinician comfort level, patterns in 
barrier identification were assessed. The results are summarized in Table 9. When broken down categorically, ethical or financial reasons were always cited as the least frequent barrier to providing effective services. Most often, preparedness was cited as the most common barrier to providing services. However, within each category there are deviations from this pattern.

Within the category of comfort level, as participants moved towards "somewhat comfortable" or "very comfortable," preparedness no longer fell within the top two most frequently identified barriers. Instead, academic relevance was listed as the most frequent barrier for "somewhat comfortable" and time was listed as the most frequent barrier for individuals who rated themselves as "very comfortable."

The relationship between clinician comfort level and select demographic variables was examined in Table 5. The following variables: geographic region, prior medical experience, and current service provision were significantly correlated with the clinician's comfort level. These variables likely affected their perception of the service barriers.

Within the region category, respondents from the south deviated from the most frequently identified limitation: preparation. In the south, clinician preparedness was ranked equally with time. Table 10 examines significant demographic variables based on region. Caseload was a variable found to be significantly correlated with region. Figure 10 displays caseload characteristics by region. It appears that clinicians in the south have higher caseloads, which could be why they feel more restricted by the time needed to provide effective feeding and swallowing services. A larger scale survey with balanced 
geographic sampling would be needed however, to determine to association between caseload size and the provision of feeding and swallowing services in the school system.

In the category of prior medical experience, clinician preparedness tied with time for the most frequent response. Referring to Table 10, caseload was again a significant variable when compared to the clinicians' prior medical experience. Figure 11 depicts caseload size based on prior medical experience. It is unclear why caseload would be correlated with prior medical experience. However, the SLPs who previously worked in a medical setting and participated in this study appear to have higher caseloads.

Within current provision of services, the type of school the SLP works at and the caseload size were found to be significantly correlated. The relationship between type of school and provision of feeding and swallowing services is difficult to analyze in this study, as most participants were from public schools. In a larger scale study with a more varied population, the type of school setting could be more carefully analyzed. It is possible that feeding and swallowing services are more common at specialty schools (e.g. a special education school) where children have more intensive, medically-based needs, like feeding and swallowing difficulties. In addition to the type of school, a significant correlation was found between caseload size and whether or not SLPs were currently providing services (Table 10). The descriptive data are shown in Figure 12. SLPs with smaller caseloads were more likely to be currently providing feeding and swallowing services.

SLPs stating time as a barrier suggests that caseload size may play a large role in determining whether children receive feeding and/or swallowing services. In total, 52/200 SLPs stated that their caseload was more than 60 students. Interestingly, within this 
sample of 52 SLPs, academic relevance, not time, was identified most frequently as the largest barrier to providing feeding and swallowing services. Time was listed as the second largest barrier, as reflected in Figure 13.

In order to better understand the impact of caseload size on service provision, a tailored and larger scale study is warranted. Although a SLPs comfort level was not found to be significantly correlated with caseload, the size of a SLPs caseload does appear to affect their perception of the barriers to providing effective services. This may affect if a child will receive feeding and swallowing services in a school and should be investigated in future research.

\subsection{Open Response Analysis}

All open responses were coded using NVivo (QSR International Ltd, 2014). General codes were used to reflect the overall theme of the open response answer. The general codes included: Accommodations, Direct Intervention, Follow Protocol Set Forth by Another Professional, Refuse Treatment or Refer to Outside Professional, and Unsure (Table 1). General codes were not mutually exclusive, with the exception of Refusing Treatment. Refusing Treatment could not be coded in the same response as Accommodations or Direct Intervention. There was significant variation in the length and depth of the participants open response answers. Due to the nature of the study, there were no minimum requirements for length of response. The researcher could not reach out to participants to ask them to expand on their answers or to verify meaning. In total, 133 open responses were analyzed. 


\subsubsection{Accommodations}

In total, $17 / 133(12.8 \%)$ participants stated that they would provide accommodations to the fictional student. Examples of the accommodations cited and the number of participant responses are listed in Table 2 . The most common plan for accommodations was to provide staff training and education (16/17 participants; $94.1 \%)$. For some participants this included training a monitor for the child to have with them during meal and snack times. Additionally, participants specified that they would put in place a written emergency plan (7/17 participants; $41.2 \%)$.

\subsubsection{Direct Treatment}

In total, 77/133 (57.9\%) participants said they would provide direct treatment. Direct intervention methods suggested in the open responses were broken down into the categories and subcategories displayed in Table 3 . The most frequently listed direct intervention method was oral motor exercises (42/77 participants; 54.5\%). Participants cited a number of reasons for completing oral motor exercises. The most frequently cited reason was to increase the child's oral and lingual strength. Most participants did not specify exactly what oral motor exercise protocol, if any, they would follow.

Diet considerations were tied for the second most frequent direct intervention method specified. A total of 35/77 participants (45.5\%) specified diet modification as a form of direct intervention. Of the 35 who specified diet modification, 15 participants $(42.9 \%)$ stated that they would follow diet modifications as provided to them and 20 participants $(57.1 \%)$ would formulate diet recommendations for the student. Some of the participants who would follow diet modifications expressed their plan to coordinate with the cafeteria to make sure the child's food was an appropriate texture and some expressed 
a plan to meet with the child's mealtime monitor to ensure food was broken into small bites.

Safe swallow techniques were cited as frequently as diet modifications. A total of 35/77 (45.5\%) participants specified using safe swallow strategies. Most participants did not specify what they meant by safe swallow techniques. The most frequent subcategory coded was having the child alternate foods and liquids. Compensatory strategies were mentioned in a similar manner. A total of 23/77 (30\%) participants mentioned the use of compensatory strategies. Many participants did not specify which compensatory strategies they would employ. However, the most common compensatory strategy mentioned was a chin tuck (9/23 participants; 27.3\%). In total, 4/23 (17.4\%) participants stated they would employ the strategies trialed in a modified barium swallow study.

Using the general category codes for direct intervention (Table 3: diet considerations, oral motor exercises, oral motor stimulation, pharyngeal exercises, safe swallow strategies, specific tools utilized, and compensatory strategies), 29 unique plans of care were proposed. On average, participants specified 2.42 general codes within their response $(n=68$, range $=1-5, S D=1.17)$. In total, 9 participants did not specify any general codes, meaning they stated they would provide direct care, but did not create an in depth treatment plan. The most common treatment plan combination was to integrate diet modifications and safe swallow strategies ( 8 participants). This plan of care was followed by participants who specified only oral motor exercises as their treatment plan (7 participants).

Using the more specific subcategory codes for direct intervention (outlined in Table 3), 61 unique plans of care were proposed. The plans of care ranged from briefly 
stating "provide oral motor exercises," to a highly involved, multistep plan. Participants who received a category code (e.g. oral motor exercises), but provided no additional detail, did not receive a subcategory code. Additionally, participants who stated they were willing to provide direct treatment, but did not provide more specific details were given no subcategory codes. In total, 61 participant responses were coded with the subcategory codes listed in Table 3. These participant's responses received between 1 and 11 subcategory codes. On average, participant's responses were given 3.56 codes $(S D=2.22)$. No participant response contained a duplicate combination of subcategory direct intervention codes.

\subsubsection{Follow Protocol Set Forth by Another Professional}

In total, $14 / 133(10.5 \%)$ participants said they would be willing to provide direct treatment if the protocol was set forth by another professional (e.g. the child's outside feeding therapist or a medical professional). This category was not mutually exclusive. These participants often overlapped with participants who were "unsure" what treatment they would provide.

\subsubsection{Unsure}

The category unsure was not mutually exclusive. Participants could be coded as willing to provide direct treatment, despite being unsure how they would go about it. In total, 42/133 (31.6\%) participants expressed they were unsure within their open response answers.

\subsubsection{Refuse Treatment or Refer to an Outside Professional}

In total, $29 / 133(21.8 \%)$ participants stated that they would not provide feeding and swallowing services in the school system. Stated reasons included SLP not being 
adequately prepared to provide such services, SLP not having the time to provide these additional services, and the services not being academically relevant. The majority of participants, however, did not specify why they would refuse treatment.

\subsubsection{Variables Affecting Open Response Direct Treatment Plans}

Demographic factors were examined to determine why some survey respondents elected to provide direct treatment as part of their treatment approach. The correlation results, shown in Table 11, indicated four factors were significantly correlated with plans to provide direct treatment: the region the SLP worked in, prior medical experience, current service provision, and self-identified comfort level. The descriptive data for each of these demographic variables are displayed in Figures 14-17.

\subsection{A Team Approach}

The 133 participants who responded to the open response case study were asked to choose their school-based interdisciplinary team members. They selected team members from the following list: physical therapist, occupational therapist, recreational therapist, school psychologist, school nurse, special education teacher, and general education teacher. Responses are outlined in Figure 18. Participants could choose to specify "other." In total, 58/133 (43.6\%) participants specified "other." The most common "other" response was including a paraprofessional or primary feeder for the child on the interdisciplinary team.

\subsection{Status of Services Currently Being Provided}

One goal of this study was to establish the types of feeding and swallowing services that are currently being provided in school systems across the United States. In total, 53/200 (26.5\%) participants indicated that they were currently providing feeding 
and swallowing services within their school system. Of these 53 participants, 52 answered the multiple choice questions that pertained to the feeding and swallowing services currently being provided by SLPs in the school system. Table 12 outlines the types of services currently being provided. The most common type of feeding and swallowing service was collaborative consultation. In total, 51/52 (98.1\%) participants stated that they engaged in some type of collaborative consultation. This included the sharing of information about the child's feeding and swallowing with team members, collaboration with teachers/paraprofessionals to ensure safe eating during snack and mealtimes, and collaboration with the child's outside feeding or medical specialists. The second most common type of service provision identified was monitoring. In total, 45/52 (86.5\%) participants said they would monitor the student. It is unclear from this study the consistency of the clinician's monitoring. It is possible that within this category, the amount of monitoring could vary greatly from daily direct supervision to checking in and monitoring monthly. Further research would have to be conducted to assess this. In addition, 38/52 (73.1\%) participants said they would engage in treatment sessions at their school. The least common type of service provision identified by participants was assessment. Only 27/52 (51.9\%) participants stated they were completing assessments of feeding and swallowing difficulties at their school.

Table 13 outlines how school-based SLPs are supported by their school district to provide feeding and swallowing services. The most common type of support identified was access to outside consultations, with 21/52 (40.4\%) participants receiving this type of support. This included feeding specialists or outside medically-based SLPs consulting with the school-based SLP to create effective treatment plans for students. In total, 15/52 
(28.8\%) of the study participants indicated that no support is offered by their school to inform their feeding and swallowing services. For the 15 participants who indicated that they receive no support, $9(60 \%)$ listed administrative support as a barrier to feeding and swallowing services, making it the second largest barrier to providing effective services for this subgroup of participants.

In addition to school-provided supports, SLPs can supplement their own knowledge using multiple resources. Table 14 outlines methods that SLPs, who are currently providing feeding and swallowing services in the schools, use to supplement their professional knowledge. The most common way they supplement their knowledge was participating in continuing education units related to feeding and swallowing. SLPs are required to complete continuing education units in order to maintain their ASHA certification. Participants were given an opportunity to select "other" and list additional sources they use to further their professional knowledge. Participants who specified their "other" responses, most frequently cited consulting with other SLPs in their professional network.

The 147 survey participants who indicated that they were not currently providing feeding and swallowing services within their school district, were asked to respond to questions about students who may benefit from feeding and swallowing services in their school. A total of 143/147 (97.3\%) participants answered these questions. In total, 97/143 (67.8\%) of respondents felt that there were students at their school who would benefit from feeding and swallowing services during the day. SLPs and clinical fellows were asked to comment on if the students were receiving any type of feeding or swallowing intervention outside of the school setting. This information is outlined in Figure 19. Most 
participants stated the children were receiving feeding and swallowing services from an outside provider. This was most commonly specified as an outpatient or private clinic. Many SLPs and clinical fellows also indicated that they were unsure if the students were receiving any outside services to treat their feeding and swallowing needs. 
CHAPTER 4

DISCUSSION

\subsection{Research Questions}

\subsubsection{Research Question 1}

What demographic variables affect a school-based SLPs self-reported comfort level in providing feeding and swallowing services?

Previous studies have indicated that prior medical experience significantly impacts a clinician's comfort level in feeding and swallowing service provision (Hutchins et al., 2011; Bailey et al., 2008). The present study substantiates this finding and further indicates geographic region and current service provision as additional factors that may play a role in determining a clinician's comfort level.

SLPs practicing in the northern part of the United States were statistically more likely to be comfortable working with pediatric feeding and swallowing in a school setting. It is unclear exactly why this is the case, although as shown in Figure 10, respondents in the north reported a lower caseload. Therefore, it is possible that lower caseloads translate to additional preparation time which may impact the clinicians comfort level in providing these services. Caseload is defined as the number of students on each clinician's caseload. Workload, however, includes all the activities related to the job of an SLP. Examples of these tasks include: preparation time, paperwork, communication with other professionals, etc. (ASHA Caseload, 2019). It is possible that more medically-complex children with multiple needs, including feeding and swallowing, would be part of a smaller caseload, but constitute a larger workload. Future studies may distinguish caseload and workload to better understand the SLPs willingness to provide these services in schools. 
Participants who had prior medical experience and who are currently providing services reported that they are significantly more comfortable working with this population in schools. This finding is consistent with previous research (Hutchins et al., 2011; Bailey et al., 2008). Interestingly, completion of pediatric dysphagia coursework was not found to be significantly correlated with clinician comfort level. However, it is unclear when the participants completed their feeding and swallowing coursework. The time since course completion and the clinicians' perceived quality of the content may impact their comfort level. In summary, we do not have a clear understanding of all of the factors which impact a clinician's comfort level, but it is likely impacted by several factors including their graduate training, continuing education content areas, and pediatric dysphagia caseload per annum. Future research is warranted to better understand the multifactorial reasons underlying a clinician's comfort level as it may impact their willingness to provide feeding and swallowing services in the school setting.

\subsubsection{Research Question 2}

What do school-based SLPs view as barriers to providing effective feeding and swallowing services in their school system?

Past research has demonstrated systematic barriers to providing feeding and swallowing services in the school (Hutchins et al., 2011). In the present study, the least common barriers to providing effective feeding and swallowing treatment were financial or ethical concerns surrounding providing these services. The most common barrier identified was clinician preparedness to provide such services, followed by feeding and swallowing services being deemed academically irrelevant in a school setting. Questioning the academic relevance of providing feeding and swallowing services in a 
school is of concern because adequate nutrition significantly affects a child's academic progress (Homer, 2015), and mealtimes play an important role in a child's socialization (Heyne, Wilkins, \& Anderson, 2012).

Survey respondents also had the opportunity to select "other" and identify a barrier to service delivery that was not mentioned in the pre-selected list. The most popular "other" response was difficulty communicating with the medical professionals that the child sees outside of the school setting. The paperwork required to authorize contact between a school, governed by FERPA privacy laws, and a medical organization, governed by HIPPA privacy laws, is likely to be seen as cumbersome and possibly overwhelming to an already busy SLP.

Demographic variables likely affect a clinician's perception of the most relevant barriers to providing services. For example, as clinician's became more comfortable providing services and gained more hands on experience in the form of medical experience or current service provision, they no longer viewed their lack of preparedness as a barrier to providing services. Instead, the relevance of the service, time constraints, and administrative support were listed as the top barriers. Region was also a demographic factor that influenced the perception of service barriers. In the south, where caseloads were significantly higher than other geographic regions, time was viewed as the greatest barrier to service provision.

\subsubsection{Research Question 3}

What types of services would be suggested by school-based SLPS when presented with a student who has oral-pharyngeal stage dysphagia? 
In total, $29 / 133$ participants $(21.8 \%)$ stated that they would refuse to provide feeding and swallowing treatment in the school system. The reasons cited included a lack of time, lack of preparation to provide these services, and the services are not considered academically relevant. It is important to note the significant number of respondents who took the time to write they did not feel confident they would be able to create an effective treatment plan (42/133 participants; $31.6 \%)$. However, over $10 \%$ of the participants said they would be willing to provide services in the school if another professional set forth a protocol (14/133 participants). This clearly reflects the participants' uncertainty, however, it may also reflect a willingness to have these services be part of a school based SLPs scope of practice. In future studies, it should be determined how many SLPs would be willing to execute feeding and swallowing services with the help of a specialist or with specific protocols set in place.

Not all participants listed why they felt uncomfortable treating feeding and swallowing disorders in schools. However, several participants expressed that they lacked the hands-on experience with this population. This is consistent with prior medical experience affecting the SLPs comfort level in treating feeding and swallowing disorders in schools. Several participants also cited that they lacked coursework in feeding and swallowing disorders. However, SLP comfort level was not found to be significantly correlated with graduate school training. It is possible that another type of more recent coursework, like continuing education coursework, that specifically targeted the schoolbased SLPs role in feeding and swallowing would have a more significant correlation. As discussed earlier, it is unclear as to how long ago participants were exposed to pediatric 
dysphagia or the quality of their coursework. Continuing education was not a focus of the present survey.

Approximately $12 \%$ of the survey respondents reported that they would provide accommodations to the child in the school system (17/133 participants). The most common type of accommodation listed was providing staff training and education (16/17 participants; 94.1\%). Listed less commonly was putting a written emergency plan in place (7/17 participants; $41.4 \%$ ). The child presented in the case study was a choking risk. Negating the use of an emergency plan would leave the school at risk for significant legal issues if something was to happen during the school day.

In total, over $57 \%$ of participants said they would be willing to provide direct treatment (77/133 participants). The most common type of direct intervention listed was oral motor exercises (42/77 participants; $54.5 \%)$. Although there is limited evidence to support the use of oral motor exercises in feeding and swallowing management, since the child was presented with oral stage deficits these strategies could be warranted. Diet considerations and the use of compensatory strategies were listed as the second most common type of direct intervention. The majority of participants stated they would modify the child's diet as necessary (20/35 participants; 57.1\%). It was unclear, however, if clinicians would communicate with a medical doctor before progressing the child's diet. Communication with medical professionals is necessary for all diet modifications and progressions. It should be noted that $3 / 35(8.6 \%)$ survey participants considering diet placed the child on a non-oral diet during the school day. This would likely be extremely unsafe and could place the child at nutritional risk as the child does not have supplemental nutrition. While the child is a safety risk due to their past choking episodes, 
the child did not aspirate during the modified barium swallow study (MBSS). It is unlikely that the SLP conducting the study would have recommended that the child being placed on a nil per os (NPO) diet at that time. If they had recommended an NPO diet, plans for supplemental nutrition would have been addressed with a medical doctor. During the school day, other nutritional methods would have to be utilized to ensure the child's safety and ensure adequate hydration and nutrition.

The most common safe swallow strategy was alternating food and liquid (15/35 participants; $42.9 \%$ ). The child in the case study presented with bilateral pharyngeal residue during their MBSS. The implementation of a liquid wash is likely aimed to decrease the presence of pharyngeal residue. Compensatory strategies were mentioned in a similar manner to the phrase "safe swallow strategies." Some compensatory strategies suggested, like a head turn, would not be considered evidence-based for this student (2/23 participants; $8.7 \%$ ). The head turn strategy is utilized in cases where individuals have unilateral residue, often due to weakness, or decreased opening of the cervical esophagus. The child presented in the case study had bilateral pharyngeal residue and adequate opening of the cervical esophagus. It is important to note that only 4/23 (17.3\%) participants specified they would use the specific compensatory strategies trialed during the MBSS. There is limited evidence behind the use of most compensatory strategies in pediatric populations. Therefore, it would be important to ensure the strategies are working during an MBSS before relying on them.

There was a significant amount of variance between proposed treatment plans. In total, 29 general plans of care were proposed. Most often, participants plan of care involved making diet considerations and implementing safe swallow strategies (8 
participants). However, no two participants listed the same diet modifications and safe swallow strategies. Although participants listed similar categorical focuses of treatment within their plans of care, no two participants duplicated an exact treatment plan. This led to over sixty unique, specific treatment plans. These results match the variations in treatment plans seen in the medical setting (Carnaby \& Harenberg 2013). This likely represents a general lack of uniform procedure for feeding and swallowing treatments in the field of speech language pathology.

A comprehensive monitoring plan would be needed to be established in order to ensure the child is utilizing safe swallow techniques or compensatory strategies appropriately during snacks and mealtimes. A child who implements these methods incorrectly places may compromise their swallow safety. There are also ethical and legal considerations for the school districts. For these reasons, a treatment plan should include accommodations, a plan for direct treatment, and continued monitoring. According to the feeding specialist consulted on this project, a complete treatment plan would include diet modification, accommodations in the form of supervision or assistance, and either compensatory or safe swallow strategies. Of the 77 individuals who reported that they would provide direct treatment, only 8 respondents (10.4\%) offered a fully integrated treatment plan.

Demographic variables were assessed against the participants open response answers to determine what variables impacted the clinicians' inclusion of direct treatment in their open response answer. Within the fictional case study, geographic region, past medical experience, current provision of feeding and swallowing services, and selfidentified comfort levels were found to be significantly correlated with indicating direct 
treatment. The following participants were the most likely to include direct service treatment in their plan of care: participants in the north, participants with past medical experience, participants who were currently providing feeding and swallowing services,

and participants who rated themselves as comfortable providing feeding and swallowing services.

Interestingly, geographic region, past medical experience, current provision of feeding and swallowing services are the same variables that affected the participant's self-identified comfort level in Table 8 . Therefore, it is possible clinician comfort level can be used as a reliable indicator for a clinician's willingness to provide feeding and swallowing services in a school setting. Therefore, school-based SLPs comfort levels should be addressed on a large scale. Future studies could aim to determine effective methods to do this.

\subsubsection{Research Question 4}

What is the status of feeding and swallowing services currently being provided in schools and how do schools support these services?

The present study was designed to gain insight into the types of feeding and swallowing services that are being provided in the school system. Almost $100 \%$ of survey participants who are currently providing feeding and swallowing services reported that they engage in collaborative consultation. Approximately 50\% of those SLPs reported that they are currently providing feeding and swallowing evaluations at their school. This finding suggests that many children are being seen for feeding and swallowing assessments at locations outside of the school setting. This supports the importance of collaborative consultation as an important piece in the student's treatment plan. It is a 
positive indicator to see that all professionals who are engaging in any type of treatment or monitoring are already engaging in the consultation process.

In order to remain educated and confident in the field of speech language pathology, schools typically provide their professionals with support to further their education. A significant number of SLPs providing feeding and swallowing services stated that they receive no support through continuing education, financial support, or outside consultations (15/52 participants). This likely has a large impact on the quality of services that school-based SLPs can provide. It also clearly affected their perception of the barriers to providing services; they were more likely to list administrative barriers in comparison to their peers who receive support from their school systems. This will have to change moving forward if schools expect their SLPs to provide effective, quality services to their students.

In this study, the 147/200 participants were not providing feeding and swallowing services in their school system. However, $67.8 \%$ of these survey respondents SLPs reported that they could identify students at their school who would benefit from this type of service being provided during the school day. This represents the growing need for effective feeding and swallowing services provided in schools.

\subsection{Clinical Implications}

The need for feeding and swallowing services in the schools is expected to grow (Lefton- Greif \& Arvedson, 2008). The present study highlights the lack of preparedness to provide feeding and swallowing services in the school systems. School-based SLPs feel uncomfortable providing this type of service. Hands on experience and other forms 
of clinical education may help increase the number of clinicians in the schools who are able to effectively provide these services.

Within the survey responses, the academic relevance of providing feeding and swallowing services in the schools was questioned. This may represent a need for a broader professional discussion on academic relevance and how feeding and swallowing management relate to education.

\subsection{Study Limitations}

This study was met with many limitations. The demographic information collected for the survey participants does not necessarily match the demographic information of the SLPs in the United States. In this study, 58\% of participants were from the Northern United States. In the most recent ASHA Schools Survey, 26.1\% of participants were from the North, $24.3 \%$ from the Midwest, $31.4 \%$ from the South and 18.2\% from the West (ASHA Schools, 2018). Therefore, within our sample, most regions would be considered underrepresented. Additionally, while caseload was analyzed in the survey it is difficult to truly evaluate. Caseload is often significantly different from workload, which was not evaluated within the survey. In this study, most participants worked in suburban, public schools. It is unknown if this is representative of where most SLPs work in the U.S. This information was not directly presented in the biannual school survey conducted by ASHA in 2018. However, since there is no current information on feeding and swallowing within school systems published on a national level, this information can be considered a starting point for the general analyses conducted.

The survey format also presented another study limitation. With any web-based survey, it is difficult to guarantee an adequate survey response rate. To encourage 
responses, participants were able to opt out of the survey at any point and skip the open response questions at the end. Responses that were less than $70 \%$ complete could not be counted in the final analysis. 133/200 participants (66.5\%) completed the survey through the open response questions. However, as discussed previously, the open-response questions were answered to varying degrees. Many participants did not provide rationale for their decision making within the case study. Due to the anonymous nature of the survey, the researcher could not reach out to participants for clarification or to request additional information.

\subsection{Conclusions}

A clinician's comfort level providing feeding and swallowing services in a school is likely a product of multiple factors. This study found that comfort level is significantly correlated with the clinician's geographic region, prior medical experience, and their current caseload. These same variables can significantly affect a clinician's perception of barriers to providing effective services. However, clinician preparedness and questioning of the academic relevance of services are consistently rated as two of the largest barriers to providing these services effectively in schools. These barriers likely reflect a need for school-based dysphagia training and advocacy for supporting a child's academic, social, and emotional goals.

Approximately $26.5 \%$ of survey respondents indicated that they are currently providing feeding and swallowing services. Over $98 \%$ of participants currently providing services indicated utilizing a collaborative consultation model, with approximately $73 \%$ of the clinicians further indicating that they would provide direct treatment. The case study results highlight the variability in direct treatment plans. This is likely reflective of 
the variability among treatment of feeding and swallowing management in schools across the United States.

\subsection{Directions for Future Research}

Future research should target a larger, more diverse groups of SLPs to concretely determine the demographic information for individuals providing these services, in order to address the barriers discussed above. Efficient ways to educate and prepare SLPs to provide these services in the schools should be examined to address the growing need for feeding and swallowing service provision in the school setting. The legal framework of academic relevance could also be examined and used to assess SLPs perception of services they provide in the schools. 
Table 1. General Codes and Descriptions for NVivo

\begin{tabular}{|c|c|c|}
\hline General NVivo Code & Description & Number of Responses* \\
\hline Accommodations & $\begin{array}{l}\text { Participants expressed they } \\
\text { would provide indirect services } \\
\text { to the child, through staff } \\
\text { education, putting written plans } \\
\text { in place, etc. }\end{array}$ & 17 \\
\hline Direct interventions & $\begin{array}{l}\text { Participants expressed they } \\
\text { would work with the child } \\
\text { directly in therapy sessions at } \\
\text { school using various techniques }\end{array}$ & 77 \\
\hline $\begin{array}{l}\text { Follow protocol set forth } \\
\text { by another professional }\end{array}$ & $\begin{array}{l}\text { Participant expressed they would } \\
\text { not be comfortable creating a } \\
\text { treatment plan, but would be } \\
\text { willing to provide direct } \\
\text { treatments based on the } \\
\text { recommendations of another } \\
\text { professional }\end{array}$ & 14 \\
\hline $\begin{array}{l}\text { Refuse treatment or refer } \\
\text { to outside professional }\end{array}$ & $\begin{array}{l}\text { Participant would not treat the } \\
\text { child at school }\end{array}$ & 29 \\
\hline Unsure & $\begin{array}{l}\text { Participants expressed } \\
\text { discomfort about creating a } \\
\text { treatment plan and/or expressed } \\
\text { they were unsure }\end{array}$ & 42 \\
\hline
\end{tabular}

*Results total more than 133 responses. Some participants fell into more than one category. For example, participant indicated they were unsure but willing to carry out direct treatment orders from another professional. Participants, however, could not indicate both direct service and refuse treatment. 
Table 2. Analysis of 17 Participants Who Indicated Accommodation Plans.

\begin{tabular}{llc}
\hline Accommodation Categories & \multicolumn{1}{c}{ Description } & Number of Responses \\
\hline Emergency planning & $\begin{array}{l}\text { Creating a written document } \\
\text { with information about the } \\
\text { child's feeding and } \\
\text { swallowing and what to do } \\
\text { in case of emergency }\end{array}$ & 7 \\
Location/ seating changes & $\begin{array}{l}\text { Having the child eat lunch } \\
\text { in a quiet environment, } \\
\text { giving the child more time } \\
\text { at meals }\end{array}$ & \\
Monitoring & $\begin{array}{l}\text { Providing a mealtime } \\
\text { monitor for the student } \\
\text { during mealtimes }\end{array}$ & 9 \\
Social accommodations & $\begin{array}{l}\text { Having friends sit with the } \\
\text { child in a modified } \\
\text { environment }\end{array}$ & 2 \\
Staff training and education & $\begin{array}{l}\text { Training the staff on safety } \\
\text { procedures, educating them } \\
\text { on signs of aspiration }\end{array}$ \\
\hline
\end{tabular}


Table 3. Analysis of 77 Participants Who Indicated Direct Treatment Plans.

\begin{tabular}{|c|c|c|c|}
\hline Categories* & Subcategories** & Description & $\begin{array}{l}\text { Number of } \\
\text { Responses }\end{array}$ \\
\hline \multirow[t]{9}{*}{ Diet Consideration } & & & 35 \\
\hline & $\begin{array}{l}\text { Ensure } \\
\text { appropriate } \\
\text { textures }\end{array}$ & $\begin{array}{l}\text { Check with cafeteria to } \\
\text { ensure they are following } \\
\text { dietary recommendations }\end{array}$ & 2 \\
\hline & $\begin{array}{l}\text { Follow diet } \\
\text { modifications }\end{array}$ & $\begin{array}{l}\text { SLP would ensure the } \\
\text { child's diet follows diet } \\
\text { modifications made by } \\
\text { another professional }\end{array}$ & 15 \\
\hline & Modify diets & $\begin{array}{l}\text { SLP would make diet } \\
\text { recommendations for the } \\
\text { student }\end{array}$ & 20 \\
\hline & NPO at school & $\begin{array}{l}\text { Child would be placed on a } \\
\text { non-oral diet while at } \\
\text { school due to safety } \\
\text { concerns }\end{array}$ & 3 \\
\hline & Progress diet & $\begin{array}{l}\text { SLP would monitor the } \\
\text { child's progress and } \\
\text { advance their diet as } \\
\text { necessary }\end{array}$ & 2 \\
\hline & $\begin{array}{l}\text { Texture } \\
\text { modification }\end{array}$ & $\begin{array}{l}\text { SLP would modify food } \\
\text { textures during the school } \\
\text { day }\end{array}$ & 8 \\
\hline & Thicken liquid & $\begin{array}{l}\text { All liquids should be } \\
\text { thickened during the school } \\
\text { day due to aspiration risk }\end{array}$ & 2 \\
\hline & Thin liquid & $\begin{array}{l}\text { All liquids should be } \\
\text { thinned during the school } \\
\text { day due to aspiration risk }\end{array}$ & 2 \\
\hline
\end{tabular}


OME for range

of motion

OME to

increase

coordination

OME to

increase

strength
OMEs to increase the child's range of motion

OMEs to increase the

9 child's oral coordination

OMEs to increase the child's oral and lingual strength
Oral Motor Stimulation
For increased oral movement

Using foods or flavors

Oral massage
Stimulation provided to

2 inside of child's mouth to promote oral and lingual structure movement

Use high flavor items to

3 promote oral movement

SLP provides oral massage to promote movement
Masako

Shaker

Alternate food During mealtimes, child and liquid would alternate food and drinks

Alternate food During mealtimes, child consistencies would alternate crunchy and soft foods 


\begin{tabular}{|c|c|c|c|}
\hline \multirow[t]{7}{*}{$\begin{array}{l}\text { Safe Swallow } \\
\text { Techniques }\end{array}$} & $\begin{array}{l}\text { Check for } \\
\text { pocketing }\end{array}$ & $\begin{array}{l}\text { SLP would check the } \\
\text { child's mouth for } \\
\text { pocketing or cue the child } \\
\text { to check their mouth for } \\
\text { pocketing }\end{array}$ & 3 \\
\hline & Cueing-general & $\begin{array}{l}\text { Cue the child during eating } \\
\text { (did not specify types of } \\
\text { cues/ what cues were for) }\end{array}$ & 3 \\
\hline & $\begin{array}{l}\text { Food placement } \\
\text { cues for better } \\
\text { chewing }\end{array}$ & $\begin{array}{l}\text { Cue the child to place food } \\
\text { on their molars for side } \\
\text { biting }\end{array}$ & 4 \\
\hline & Modeling & $\begin{array}{l}\text { Provide adult or peer } \\
\text { modeling during the meal }\end{array}$ & 1 \\
\hline & $\begin{array}{l}\text { Positioning } \\
\text { upright }\end{array}$ & $\begin{array}{l}\text { Provide seating that helps } \\
\text { the child sit upright during } \\
\text { meals }\end{array}$ & 6 \\
\hline & $\begin{array}{l}\text { Reduce rate of } \\
\text { intake }\end{array}$ & $\begin{array}{l}\text { Cue the child for slower } \\
\text { intake, use external pacing } \\
\text { techniques }\end{array}$ & 6 \\
\hline & Small bites & $\begin{array}{l}\text { Provide the child with } \\
\text { small bites of food }\end{array}$ & 11 \\
\hline \multirow[t]{7}{*}{$\begin{array}{l}\text { Specific tools } \\
\text { utilized }\end{array}$} & & & 13 \\
\hline & Chewy tube & Specific tool mentioned & 5 \\
\hline & $\begin{array}{l}\text { Foods for oral } \\
\text { stimulation }\end{array}$ & $\begin{array}{l}\text { Flavorful or favorite foods } \\
\text { used during therapy }\end{array}$ & 3 \\
\hline & IOPI & Specific tool mentioned & 1 \\
\hline & Mesh feeder & Specific tool mentioned & 2 \\
\hline & $\begin{array}{l}\text { Modified } \\
\text { utensils }\end{array}$ & $\begin{array}{l}\text { Trial different utensils to } \\
\text { help the child eat }\end{array}$ & 2 \\
\hline & $\begin{array}{l}\text { Non-food } \\
\text { chewy }\end{array}$ & Utilize a chew toy & 2 \\
\hline
\end{tabular}




\begin{tabular}{llll}
\hline $\begin{array}{l}\text { Specific tools } \\
\text { utilized }\end{array}$ & $\begin{array}{l}\text { Stick shaped } \\
\text { foods }\end{array}$ & Utilize stick shaped foods & 1 \\
$\begin{array}{l}\text { Z-vibe } \\
\text { strategies }\end{array}$ & Specific tool mentioned & 3 \\
& Chin tuck & Specific method mentioned & 9 \\
& $\begin{array}{l}\text { Effortful/hard } \\
\text { swallow }\end{array}$ & Specific method mentioned & 4 \\
& Head turn & Specific method mentioned & 2 \\
& $\begin{array}{l}\text { MBSS trialed } \\
\text { strategies }\end{array}$ & $\begin{array}{l}\text { SLP would review the } \\
\text { MBSS report and use } \\
\text { strategies trialed during the } \\
\text { report }\end{array}$ & 4 \\
& $\begin{array}{l}\text { Specific method mentioned } \\
\text { maneuver }\end{array}$ & 2 \\
& Second swallow & Specific method mentioned & 7 \\
& $\begin{array}{l}\text { Supraglottic } \\
\text { swallow }\end{array}$ & Specific method mentioned & 3 \\
Tongue sweep & Specific method mentioned & 2 \\
\hline
\end{tabular}

*All 77 participants who indicated providing direct intervention fell into at least 1 category. Participants could be placed in more than one category and no categories were mutually exclusive. Therefore, results total more than 77 responses.

**Not all participants specified subcategories. Participants could be coded for more than one subcategory response. Some subcategories were mutually exclusive (e.g. within the category diet modifications: the response could not be coded as thin liquids and NPO, but could be coded as texture modification and thin liquids). 
Table 4. Current School-based Service Provision.

\begin{tabular}{lcc}
\hline Certification Status & + Providing Services & - Providing Services \\
\hline ASHA-Certified & 47 & 136 \\
Clinical Fellows & 6 & 11 \\
\hline Total $(n=200)$ & 53 & 147 \\
\hline
\end{tabular}


Table 5. Pediatric Dysphagia Graduate School Training

\begin{tabular}{lcc}
\hline Certification Status & + Pediatric & - Pediatric \\
& Dysphagia & Dysphagia \\
\hline ASHA-Certified & 105 & 78 \\
Clinical Fellows & 14 & 3 \\
\hline Total $(n=200)$ & 119 & 81 \\
\hline
\end{tabular}


Table 6. Years of Experience by Setting.

\begin{tabular}{lccc}
\hline Setting & Respondents & \multicolumn{2}{c}{ Years of Experience } \\
& $(n)$ & Average & Range \\
\hline Education & $200 / 200$ & 11.7 & $0.5-40$ \\
Medical Inpatient & $72 / 200$ & 4.1 & $0.5-25$ \\
Medical Outpatient & $57 / 200$ & 5.1 & $0.5-25$ \\
Early Intervention & $70 / 200$ & 5.4 & $0.5-25$ \\
\hline
\end{tabular}


Table 7. Comfort Level Providing Feeding and Swallowing Services in School Setting. Number of Respondents Shown Across a 5-Point Likert Scale.

\begin{tabular}{lccccc}
\hline Certification Status & \multicolumn{5}{c}{ Level of Comfort Rating } \\
& 1 & 2 & 3 & 4 & 5 \\
\hline ASHA-Certified & 68 & 72 & 19 & 29 & 25 \\
Clinical Fellows & 5 & 6 & 2 & 2 & 2 \\
\hline Totals $(n=200)$ & 73 & 48 & 21 & 31 & 27 \\
\hline $\begin{array}{l}\text { 1= Very Uncomfortable; } 2=\text { Somewhat Uncomfortable; } 3=\text { Neutral; 4= Somewhat Comfortable; 5= Very } \\
\text { Comfortable }\end{array}$
\end{tabular}


Table 8. Results of Correlation Analysis.

\begin{tabular}{llc}
\hline Variable & \multicolumn{2}{c}{ Pearson Chi-Square Value } \\
\hline & Test-statistic & $p$-value \\
\hline Pediatric dysphagia coursework & $\chi^{2}(4)=2.765$ & .598 \\
Region & $\chi^{2}(12)=24.163$ & $.019^{*}$ \\
School type & $\chi^{2}(16)=12.097$ & .737 \\
School area & $\chi^{2}(16)=17.180$ & .374 \\
Medical experience & $\chi^{2}(4)=29.592$ & $<0.001^{*}$ \\
Caseload & $\chi^{2}(16)=14.582$ & .555 \\
Currently providing services & $\chi^{2}(4)=29.800$ & $<0.001^{*}$ \\
Years of experience in school setting & $\chi^{2}(164)=150.793$ & .762 \\
\hline
\end{tabular}

${ }^{\wedge}$ Clinician Comfort Level was the Basis of Comparison.

*Significant at 0.05 . 
Table 9. Themes in Identified Barriers.

\begin{tabular}{|c|c|c|c|c|}
\hline \multirow[b]{2}{*}{ Barriers } & \multirow[b]{2}{*}{ Subcategories } & \multicolumn{3}{|c|}{ Barriers } \\
\hline & & $\begin{array}{c}\text { Most } \\
\text { frequent }\end{array}$ & $2^{\text {nd }}$ most frequent & $\begin{array}{c}\text { Least } \\
\text { frequent }\end{array}$ \\
\hline Comfort & Very uncomfortable & Preparedness & Relevance & Finances \\
\hline \multirow[t]{4}{*}{ Level } & Somewhat uncomfortable & Preparedness & Time & Finances \\
\hline & Neutral & Preparedness & Relevance/Time & Ethics \\
\hline & Somewhat comfortable & Relevance & Time & Finances \\
\hline & Very comfortable & Time & Administrative & Ethics \\
\hline \multirow[t]{4}{*}{ Region } & North & Preparedness & Relevance & Finances \\
\hline & South & Prep/Time & Prep/Time & Ethics \\
\hline & Midwest & Preparedness & Relevance & Finances \\
\hline & West & Preparedness & Relevance/Ethics & Finances \\
\hline Past & No & Preparedness & Relevance & Finances \\
\hline $\begin{array}{l}\text { Medical } \\
\text { Experience }\end{array}$ & Yes & Relevance & Time & Fin/Ethics \\
\hline Current & No & Preparedness & Relevance & Finances \\
\hline $\begin{array}{l}\text { Provision } \\
\text { of Services }\end{array}$ & Yes & Prep/Time & Prep/Time & Ethics \\
\hline
\end{tabular}


Table 10. Significant Demographic Variables for Differences in Identified Barrier Patterns.

\begin{tabular}{llll}
\hline $\begin{array}{l}\text { Basis of } \\
\text { Comparison }\end{array}$ & Variables Compared & Test Statistic & p-value \\
\hline Region & Pedi dysphagia coursework & $\chi^{2}(3)=4.645$ & .200 \\
& School type & $\chi^{2}(12)=10.418$ & .579 \\
& School area & $\chi^{2}(12)=14.566$ & .266 \\
& Caseload & $\chi^{2}(12)=35.486$ & $<0.001^{*}$ \\
& & & \\
Past Medical & Pedi dysphagia coursework & $\chi^{2}(1)=.578$ & .444 \\
Experience & School type & $\chi^{2}(4)=4.351$ & .361 \\
& School area & $\chi^{2}(4)=3.383$ & .496 \\
& Caseload & $\chi^{2}(4)=15.858$ & $.003^{*}$ \\
& & & \\
Current & Pedi dysphagia coursework & $\chi^{2}(1)=.229$ & .633 \\
Provision of & School type & $\chi^{2}(4)=25.507$ & $<.0001^{*}$ \\
Services & School area & $\chi^{2}(4)=1.610$ & .807 \\
& Caseload & $\chi^{2}(4)=9.886$ & $.042^{*}$ \\
\hline
\end{tabular}

*Significant at 0.05 . 
Table 11. Significance of Variables Affecting the Provision of Direct Treatment in Open Response Answers

\begin{tabular}{llc}
\hline Variable & \multicolumn{2}{c}{ Pearson Chi-Square Value } \\
& \multicolumn{1}{c}{ Test-statistic } & \\
& $\chi^{2}(1)=2.982$ & .084 \\
Pediatric dysphagia coursework & $\chi^{2}(3)=8.045$ & $.045^{*}$ \\
Region & $\chi^{2}(4)=1.979$ & .740 \\
School type & $\chi^{2}(3)=1.168$ & .761 \\
School area & $\chi^{2}(1)=12.105$ & $.001^{*}$ \\
Medical experience & $\chi^{2}(4)=7.832$ & .098 \\
Caseload & $\chi^{2}(1)=19.452$ & $<0.001^{*}$ \\
Currently providing services & $\chi^{2}(4)=34.397$ & $<0.001^{*}$ \\
Comfort level & & \\
\hline
\end{tabular}


Table 12. Feeding and Swallowing Services Currently Provided by SLP in School Setting ( $\mathrm{n}=52$ respondents).

\begin{tabular}{ll}
\hline Type of Service & Respondents $(n)$ \\
\hline Monitoring & 45 \\
Collaborative consultation & 51 \\
Assessments of feeding and swallowing difficulties & 27 \\
Treatment sessions for feeding and swallowing & 38 \\
\hline
\end{tabular}


Table 13. District Supports for Feeding and Swallowing Services in School Setting $(n=52$ respondents).

\begin{tabular}{ll}
\hline Support Offered & Respondents $(n)$ \\
\hline Continuing education & 16 \\
Financial support & 13 \\
Outside consultations & 21 \\
Other & 4 \\
None & 15 \\
\hline
\end{tabular}


Table 14. Professional Knowledge Supplementation ( $\mathrm{n}=52$ respondents).

\begin{tabular}{ll}
\hline Supplemental Knowledge Source & Respondents $(n)$ \\
\hline Continuing education credits & 43 \\
ASHA Special Interest Group 13* & 9 \\
Journals/research & 33 \\
Community forums & 25 \\
Other & 11 \\
\hline *Swallowing and Swallowing Disorders (Dysphagia) &
\end{tabular}

*Swallowing and Swallowing Disorders (Dysphagia) 
Part A:

8 Demographic questions (type of school, caseload, characteristics, experience, etc.)

Are you currently providing feeding and swallowing services in your school?

Yes:

- Feeding and swallowing caseload characteristics

- Comfort regarding service provision

- Types of services provided

- Support provided

- Barriers to effective services

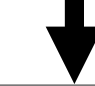




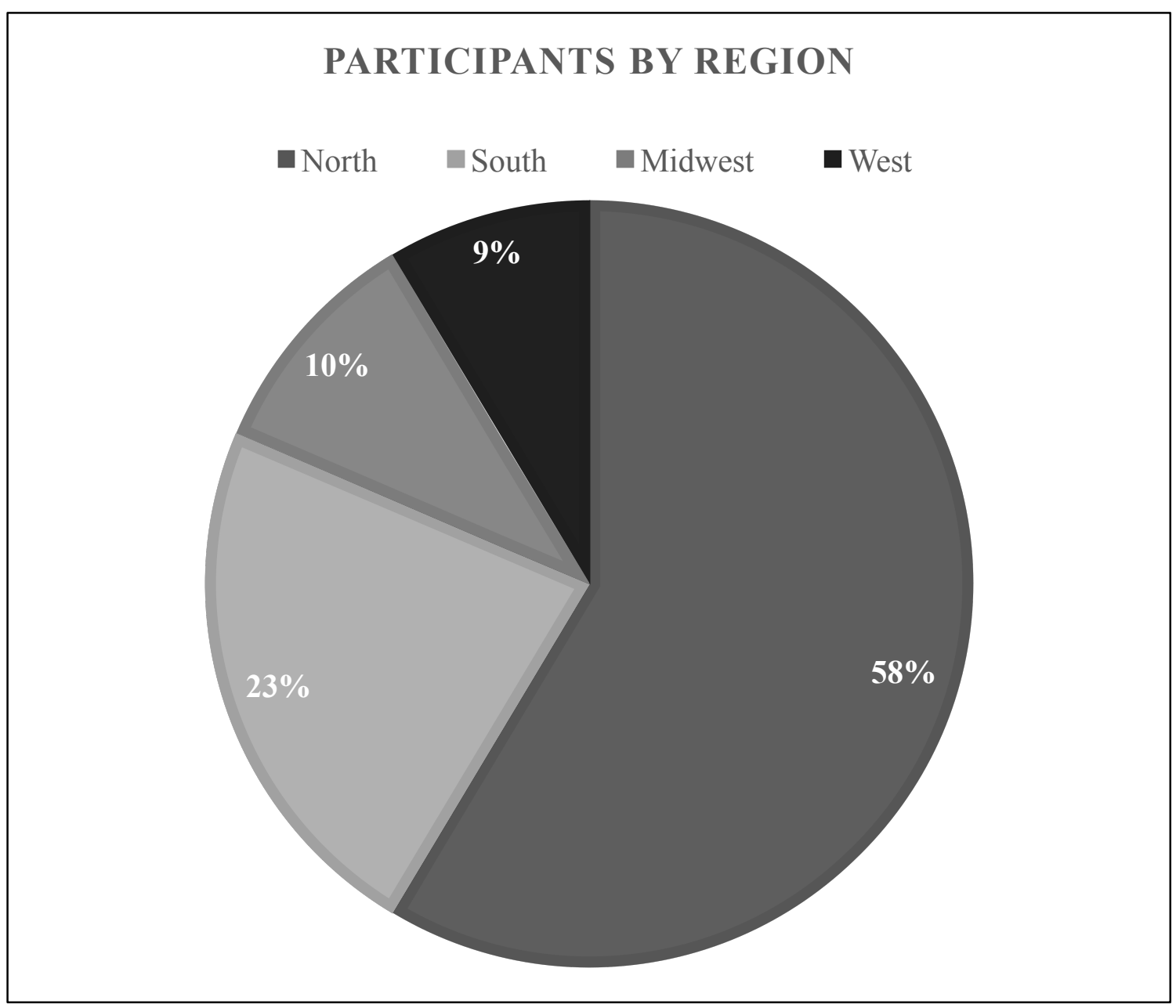

Figure 2. Participants by Region 


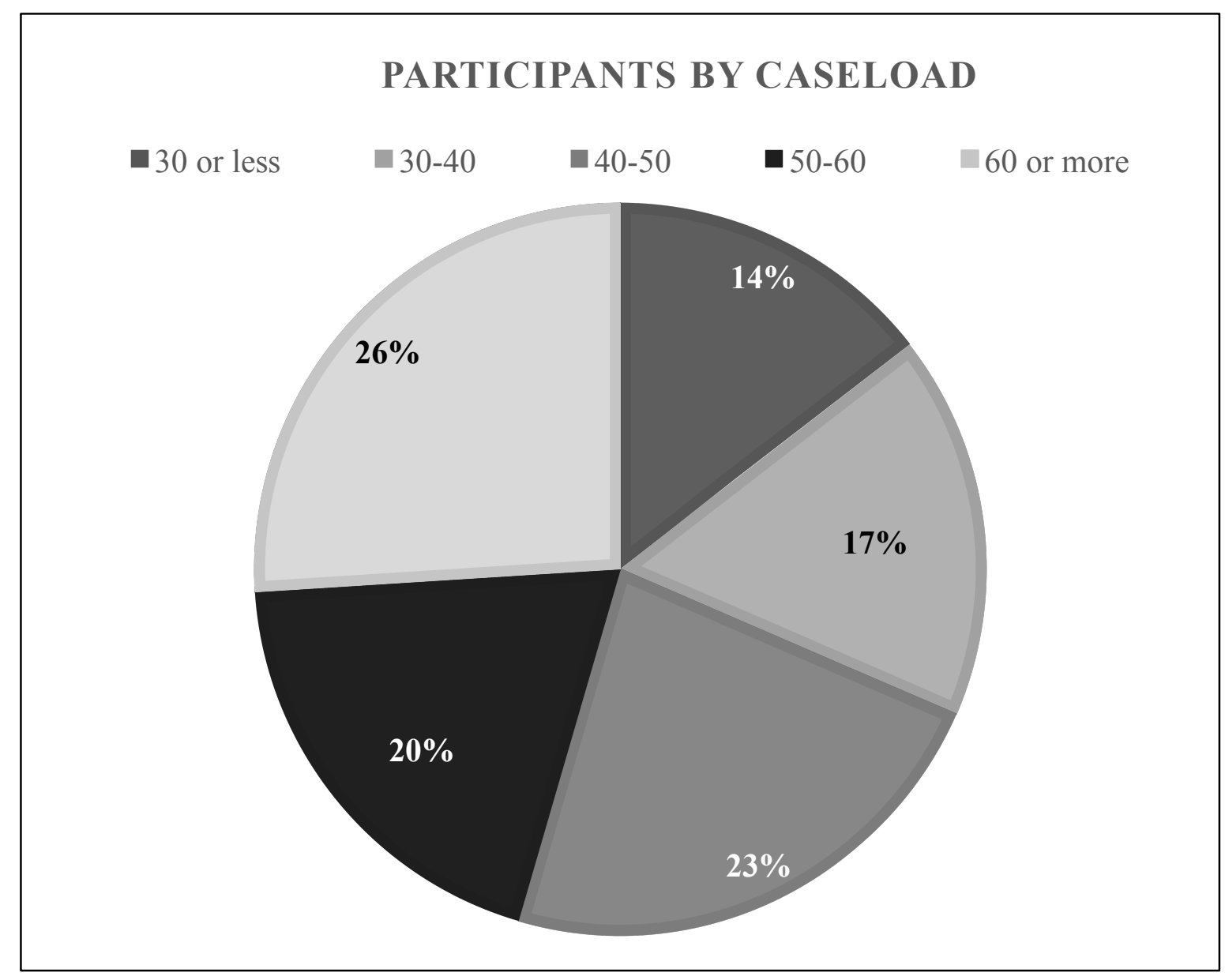

Figure 3. Participants by Caseload 


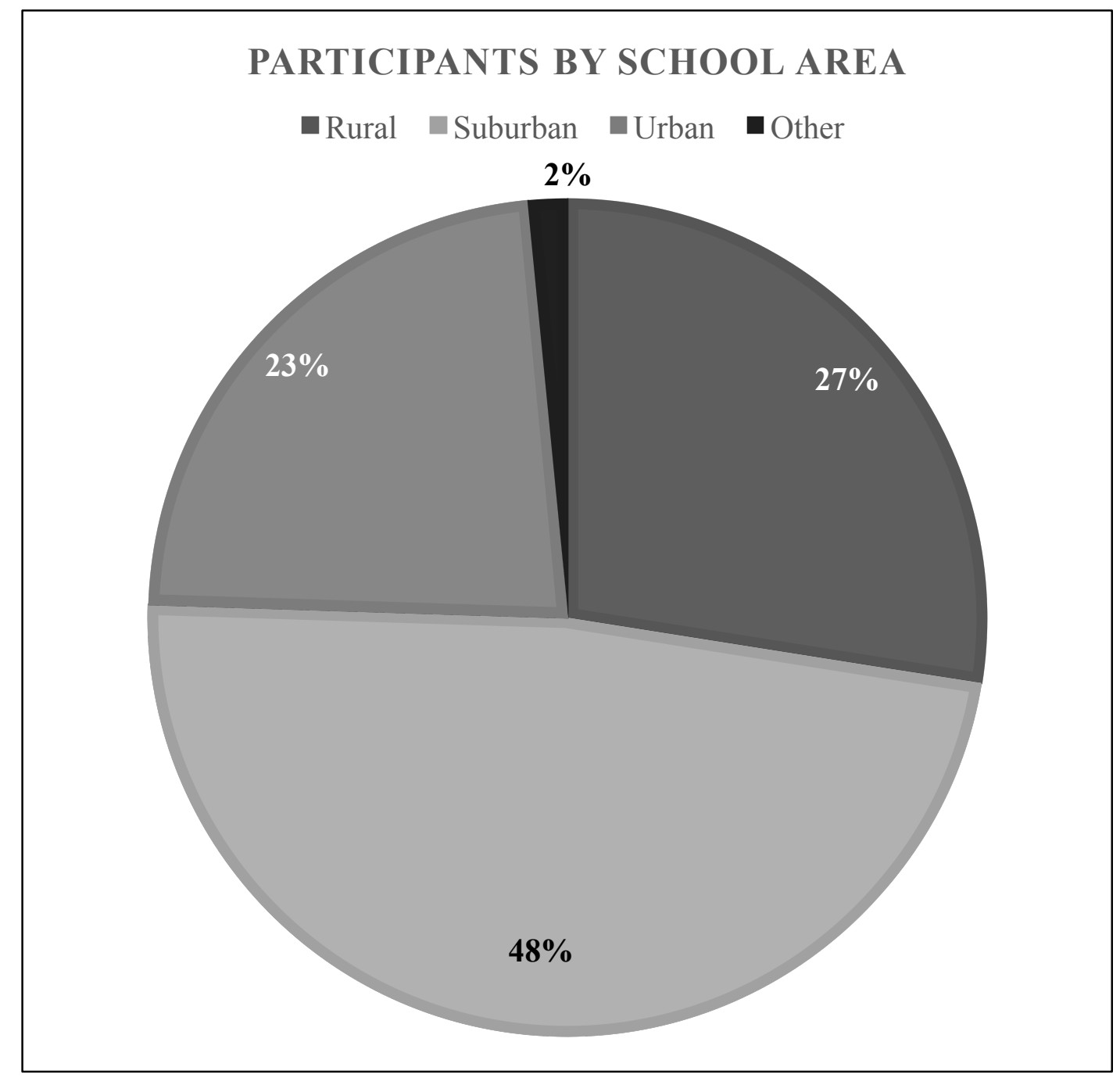

Figure 4. Participants by School Area 


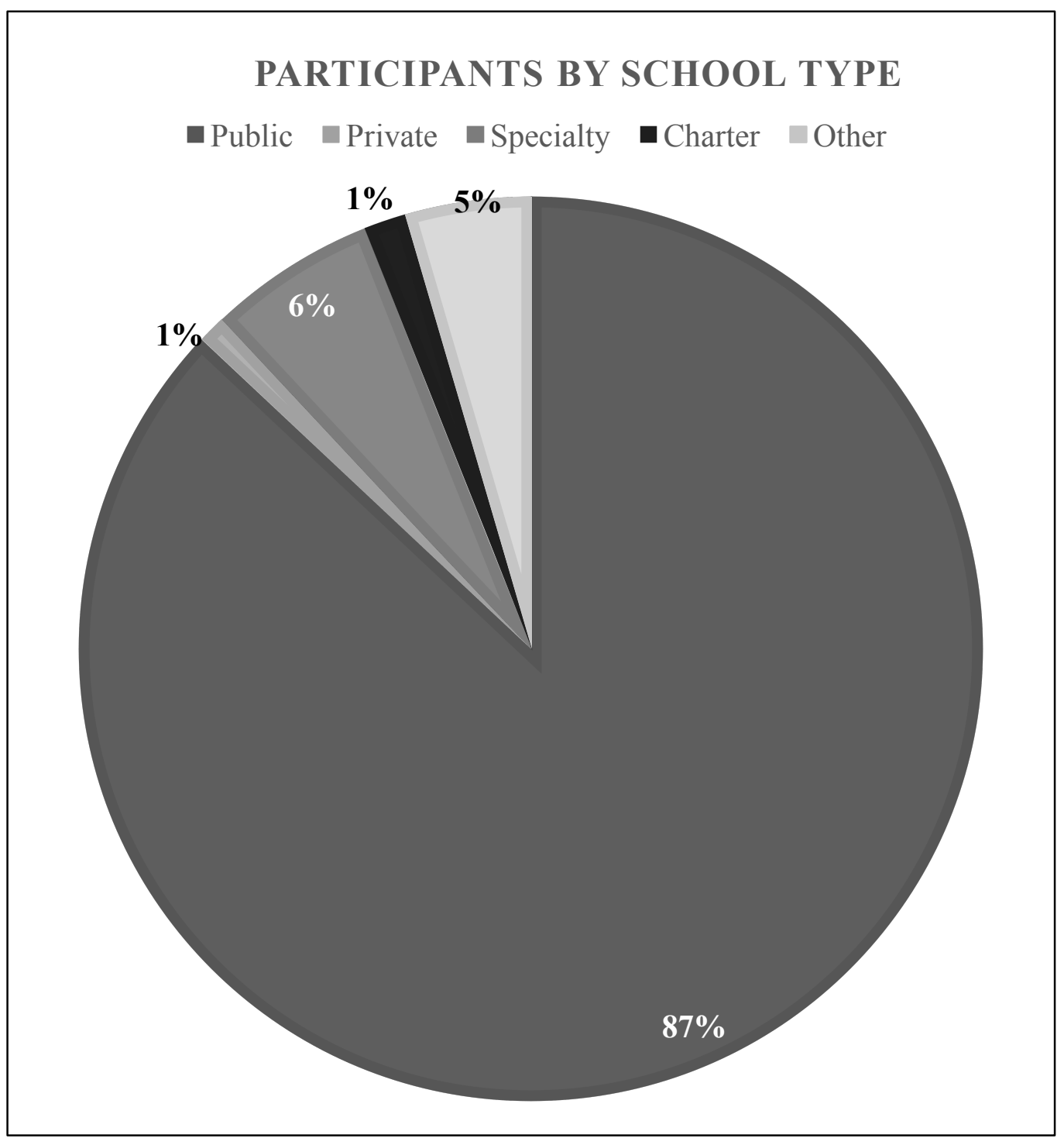

Figure 5. Participants by School Type 


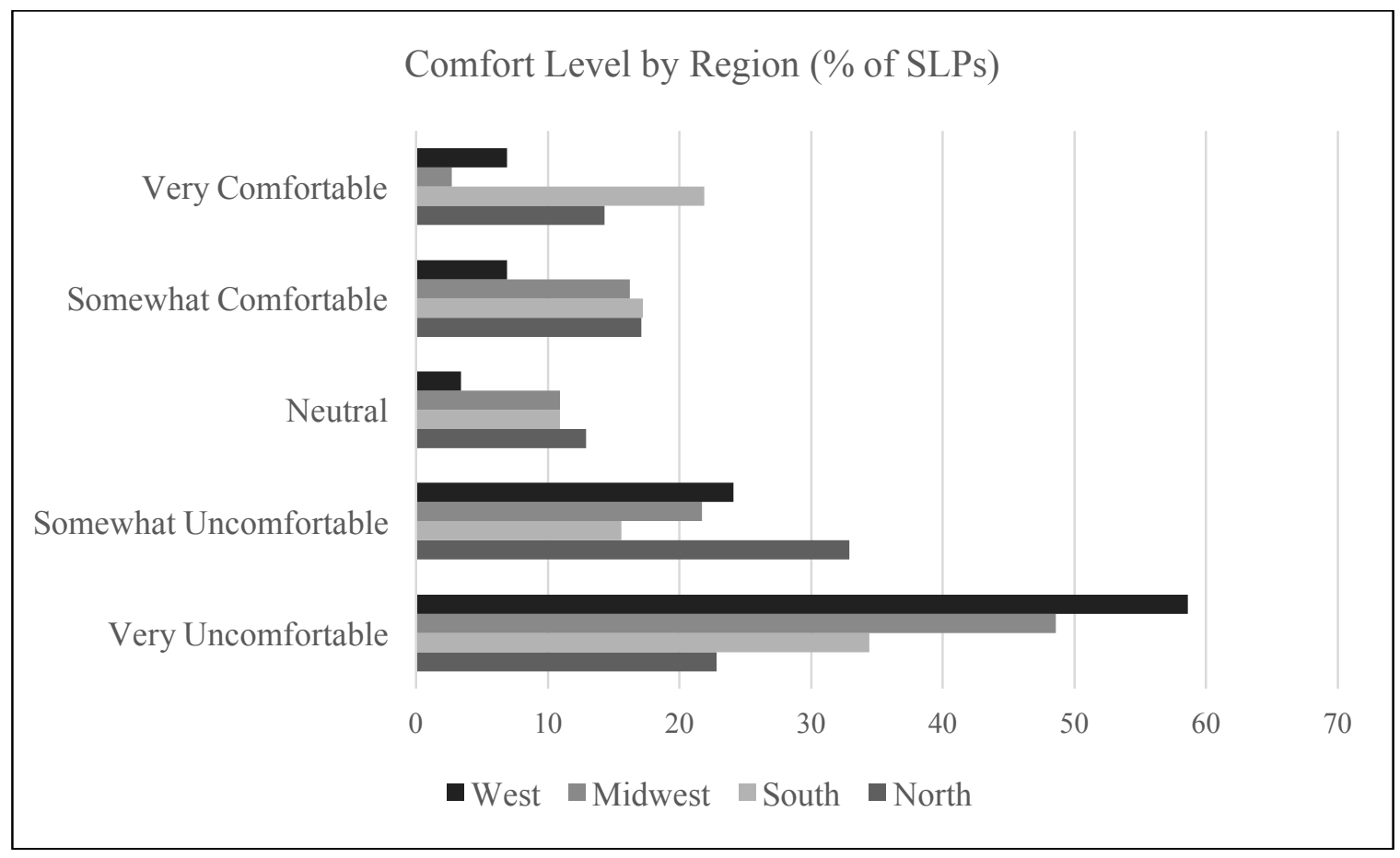

Figure 6. Comfort Level by Region (\% of SLPs) 


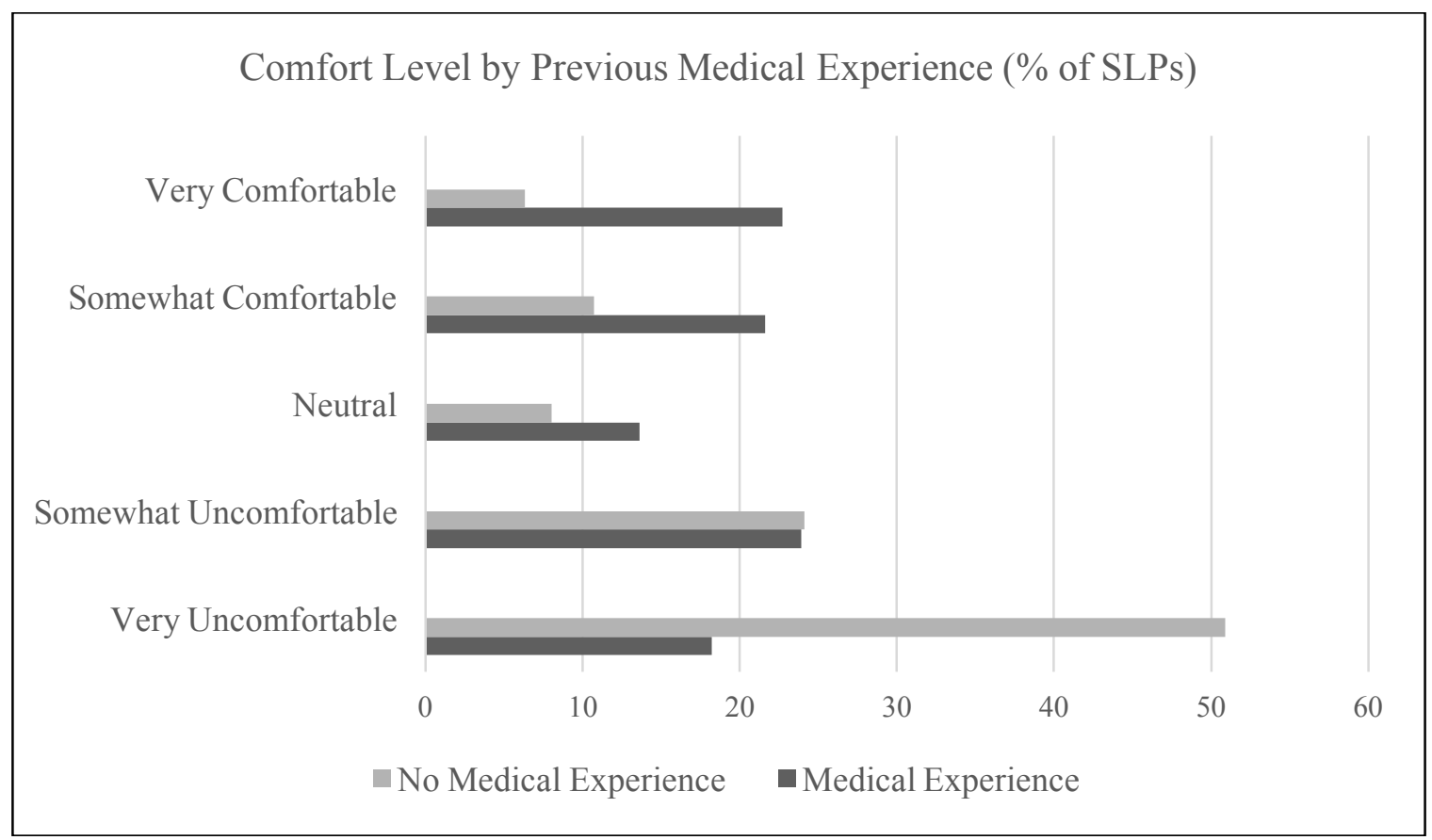

Figure 7. Comfort Level by Previous Medical Experience (\% of SLPs) 


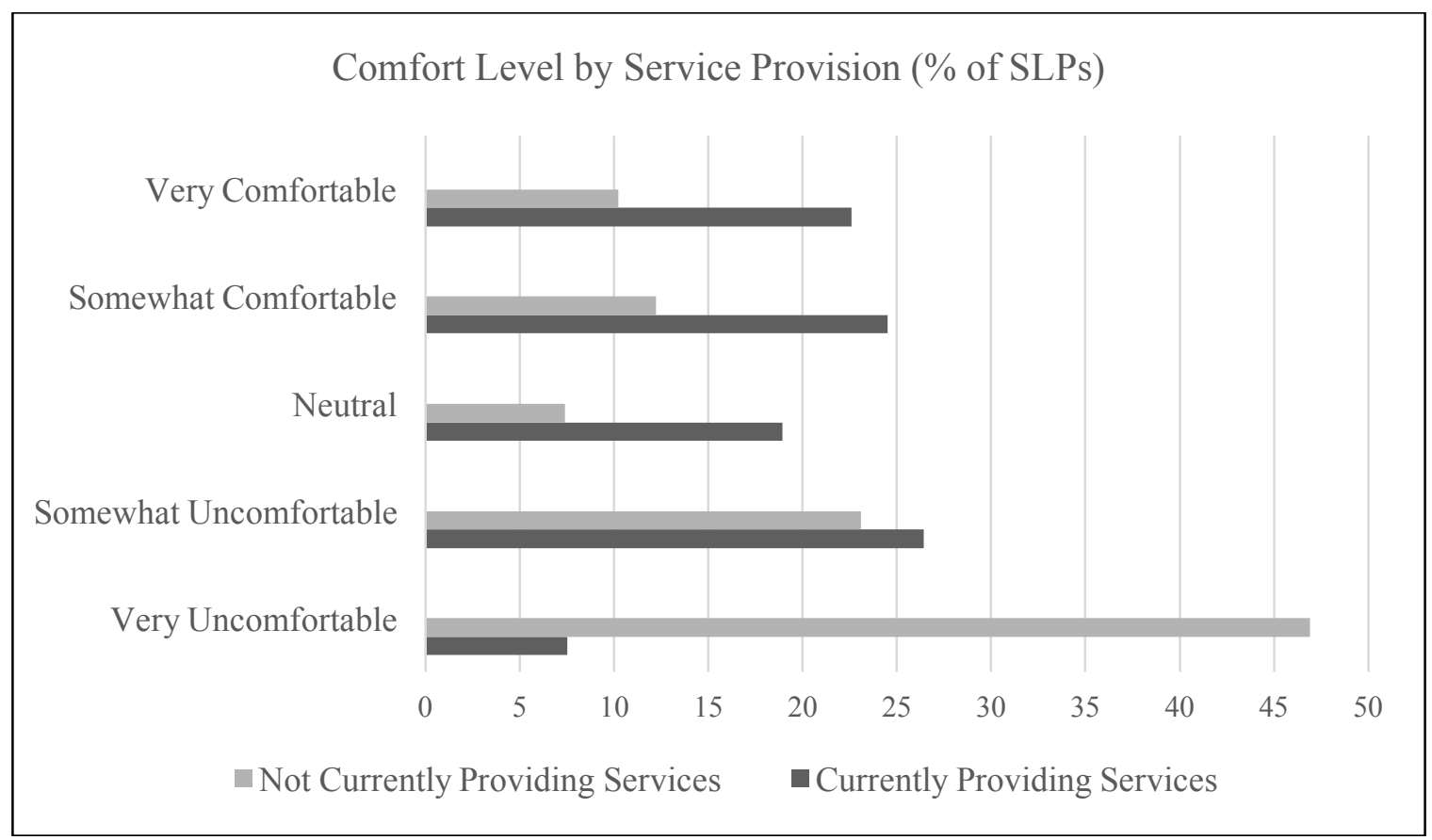

Figure 8. Comfort Level by Service Provision (\% of SLPs) 


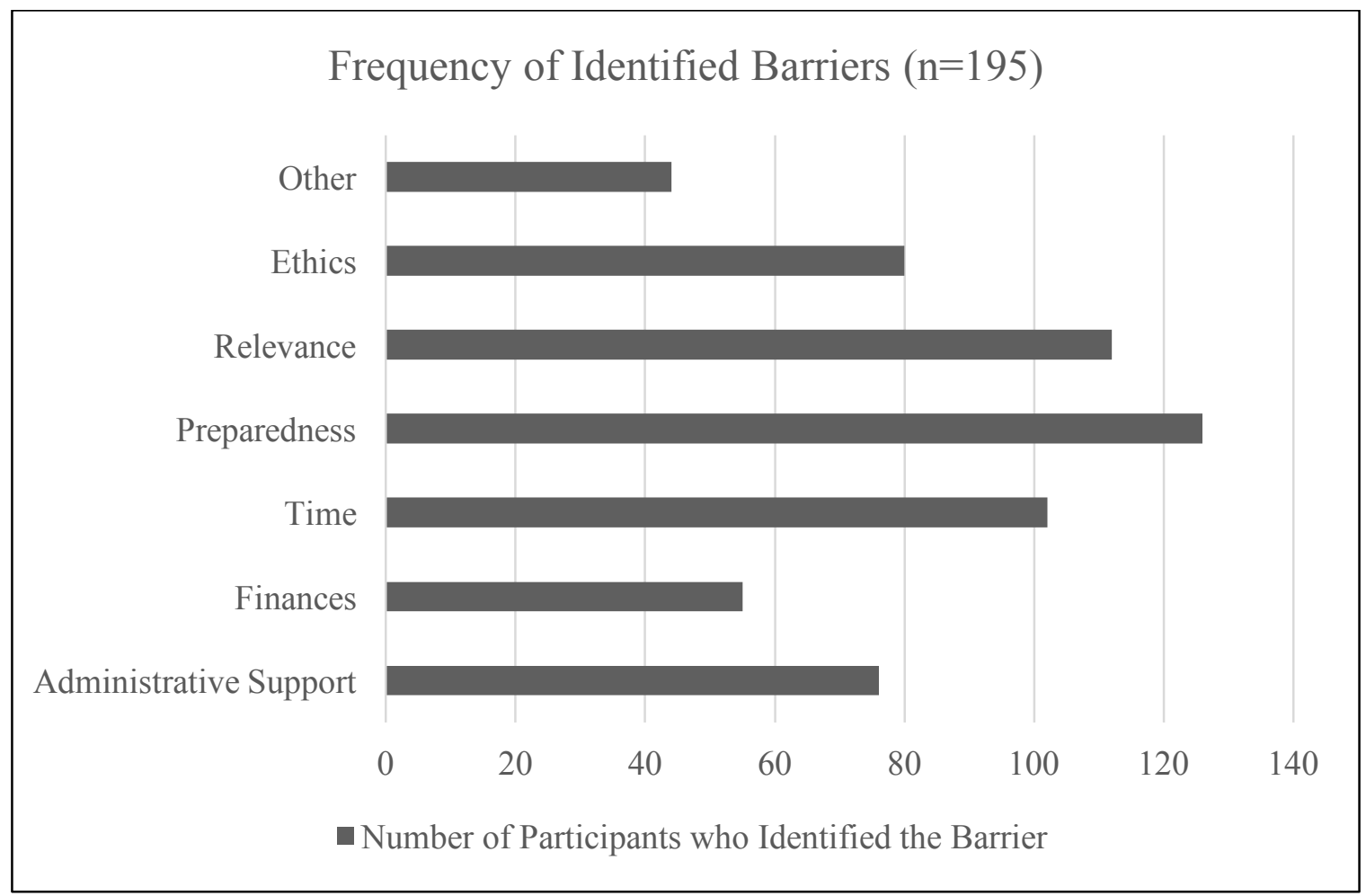

Figure 9. Frequency of Identified Barriers $(n=195)$ 


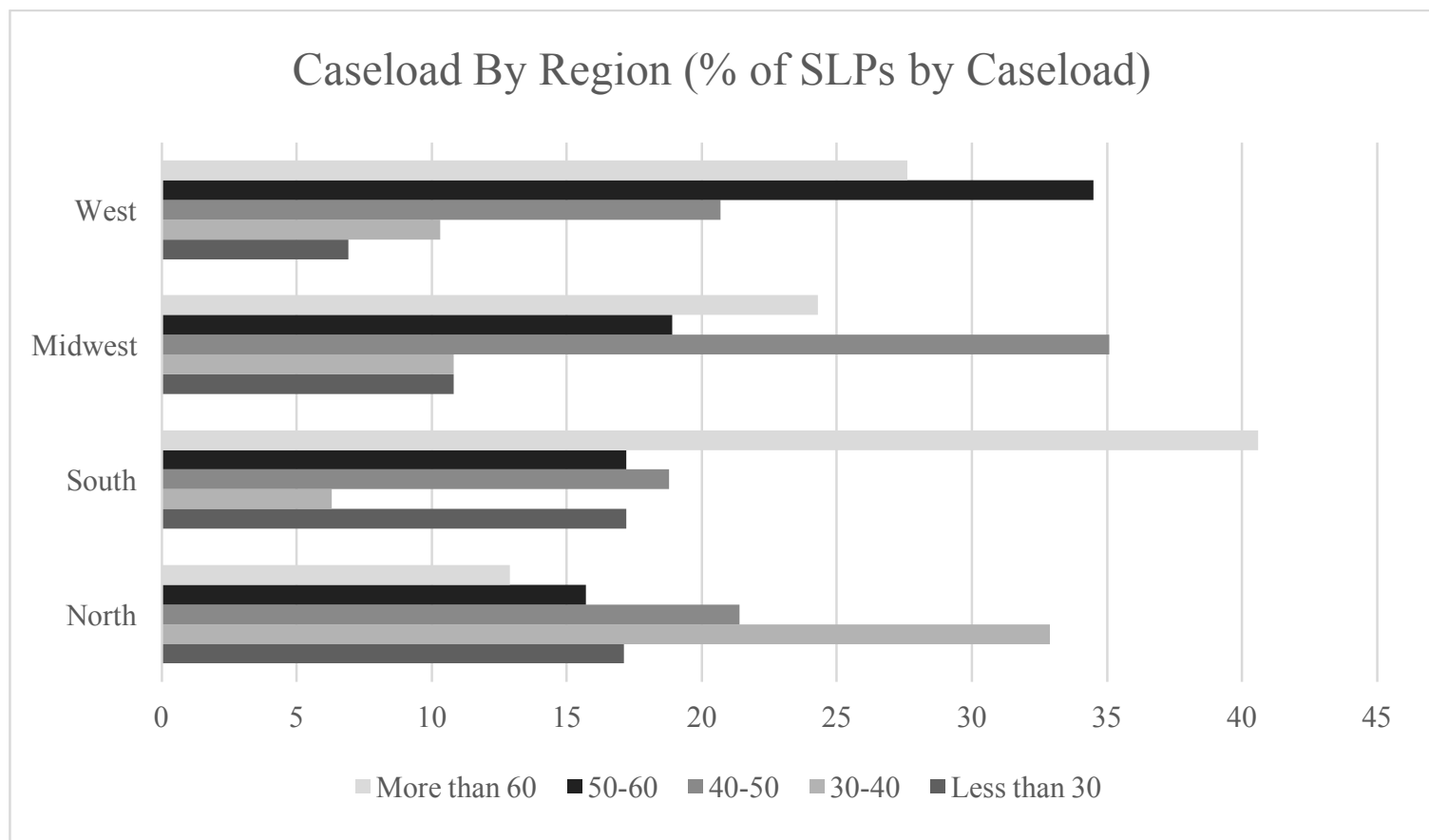

Figure 10. Caseload by Region (\% of SLPs by Caseload) 


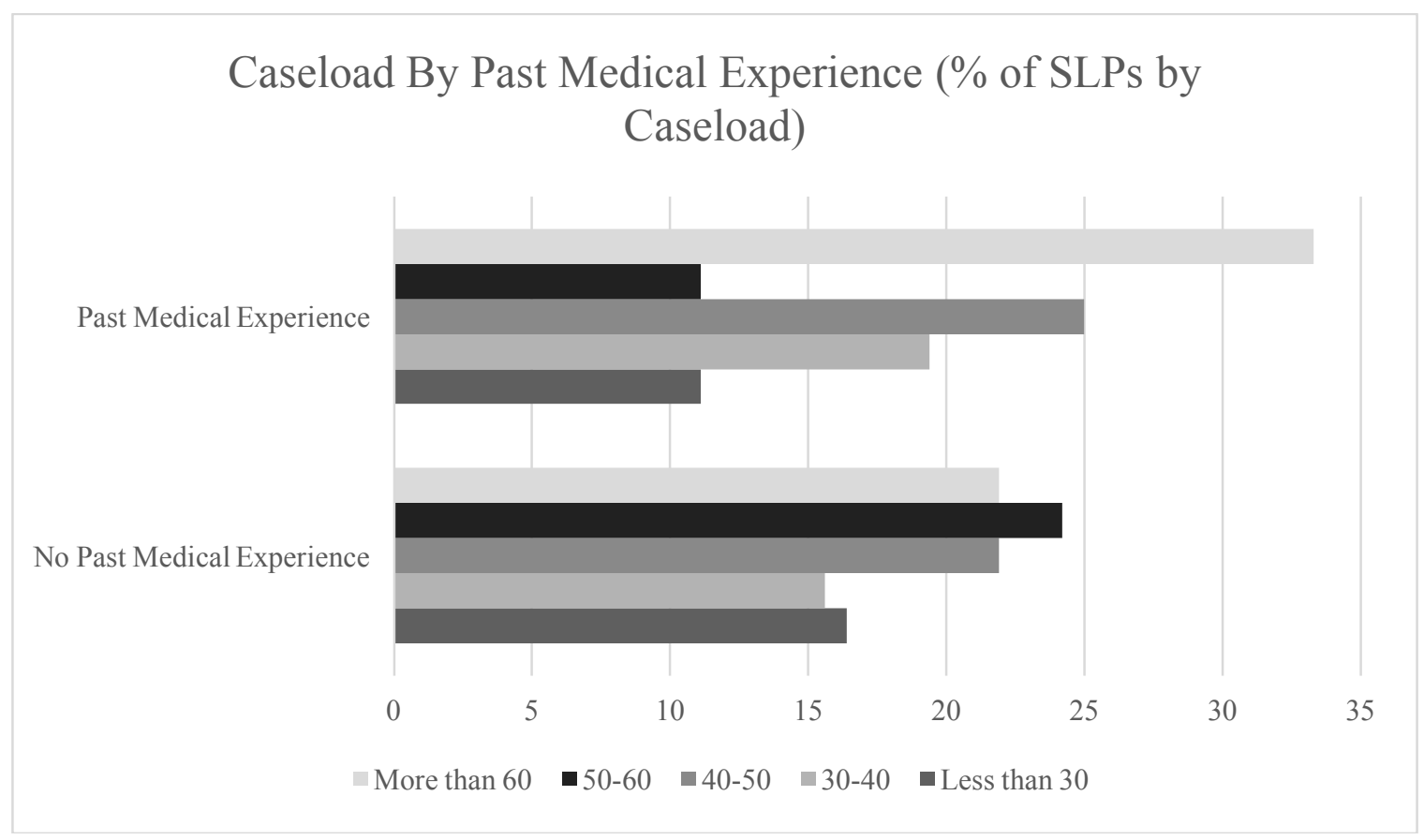

Figure 11. Caseload by Past Medical Experience (\% of SLPs by Caseload) 


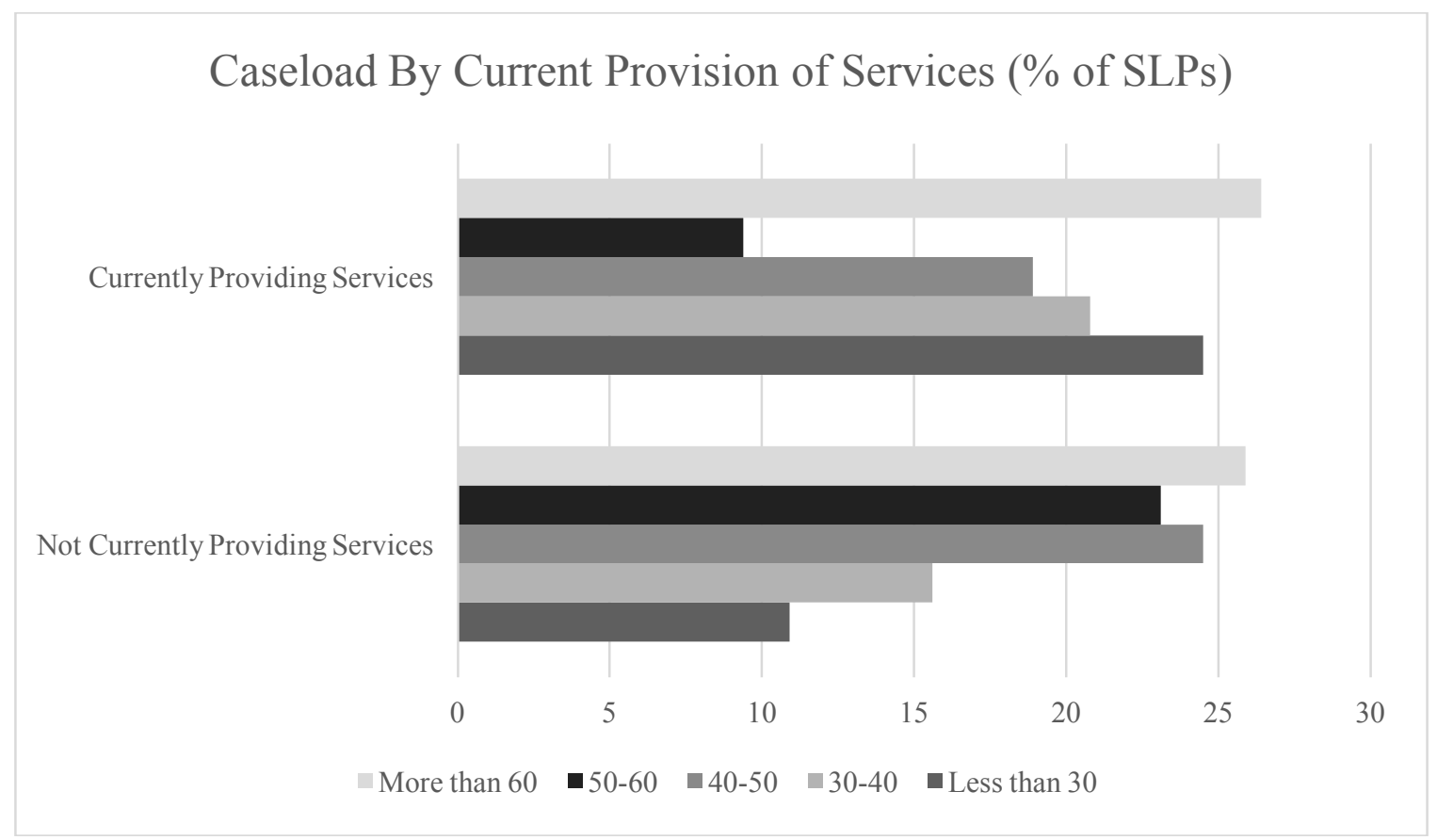

Figure 12. Caseload by Current Provision of Services (\% of SLPs) 


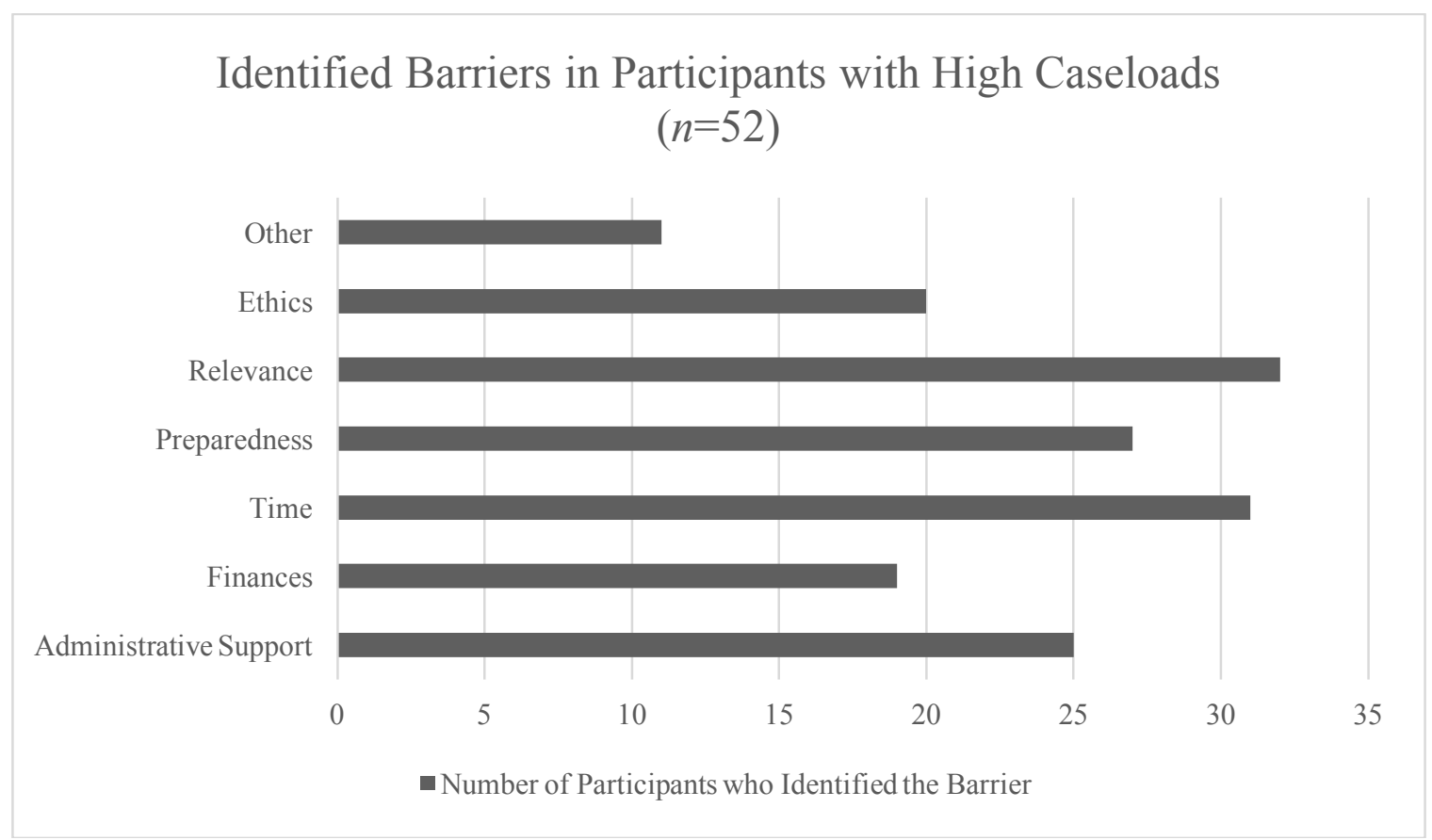

Figure 13. Identified Barriers in Participants with High Caseloads $(n=52)$ 


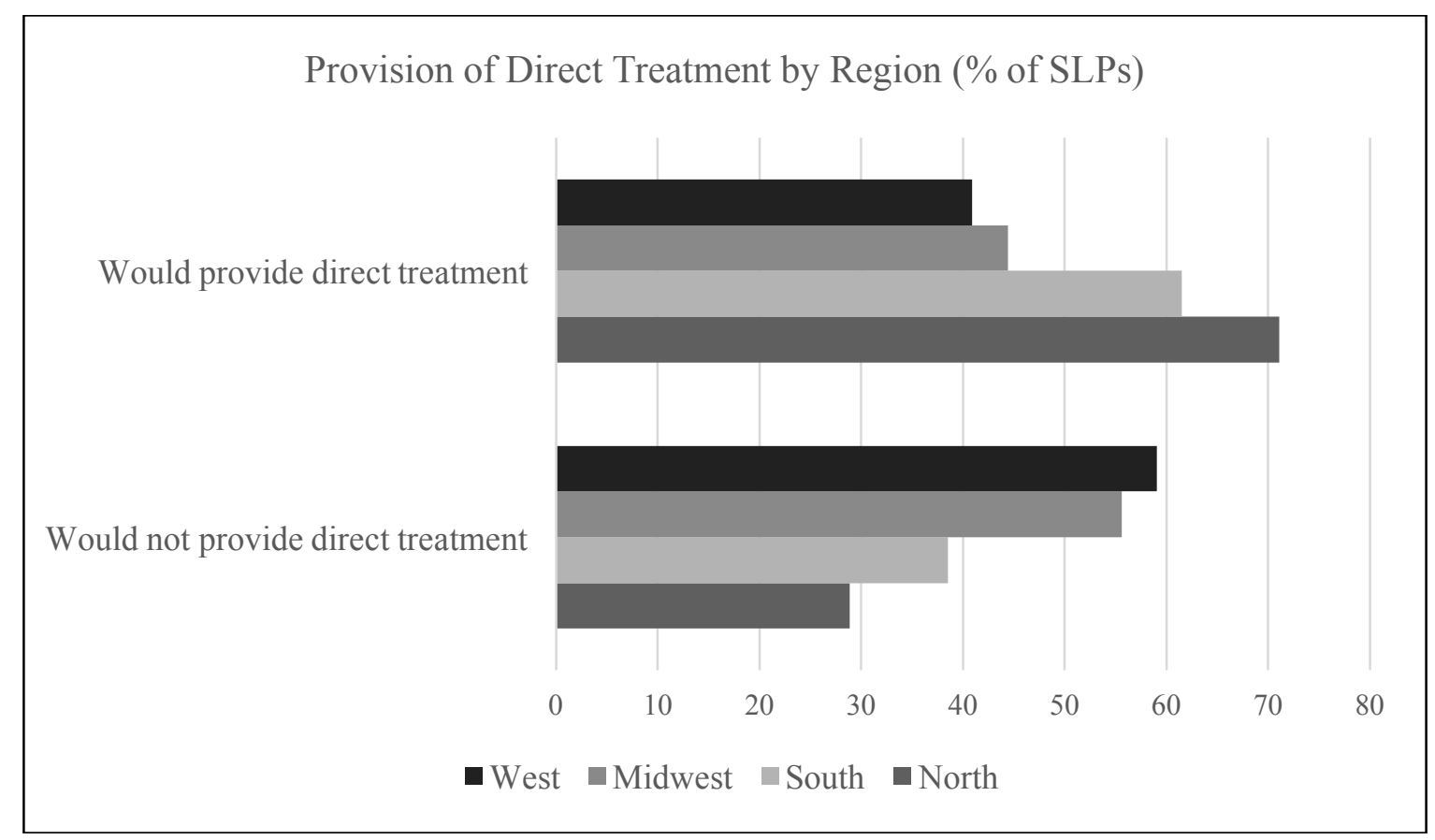

Figure 14. Provision of Direct Treatment by Region (\% of SLPs) 


\section{Provision of Direct Treatment by Prior Medical Experience (\% of}

SLPs)

Would provide direct treatment

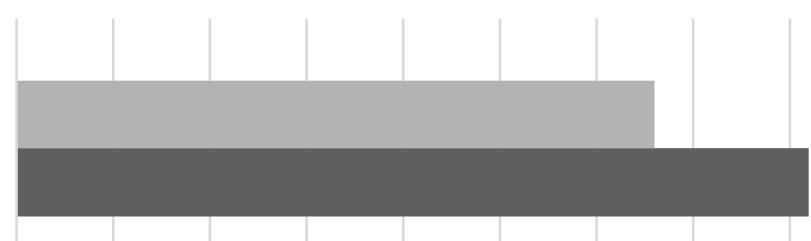

Would not provide direct treatment

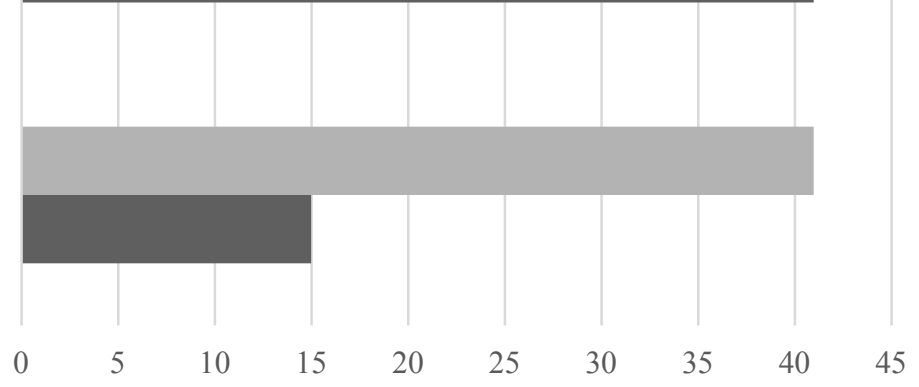

- No past medical experience

- Past medical experience

Figure 15. Provision of Direct Treatment by Prior Medical Experience (\% of SLPs) 


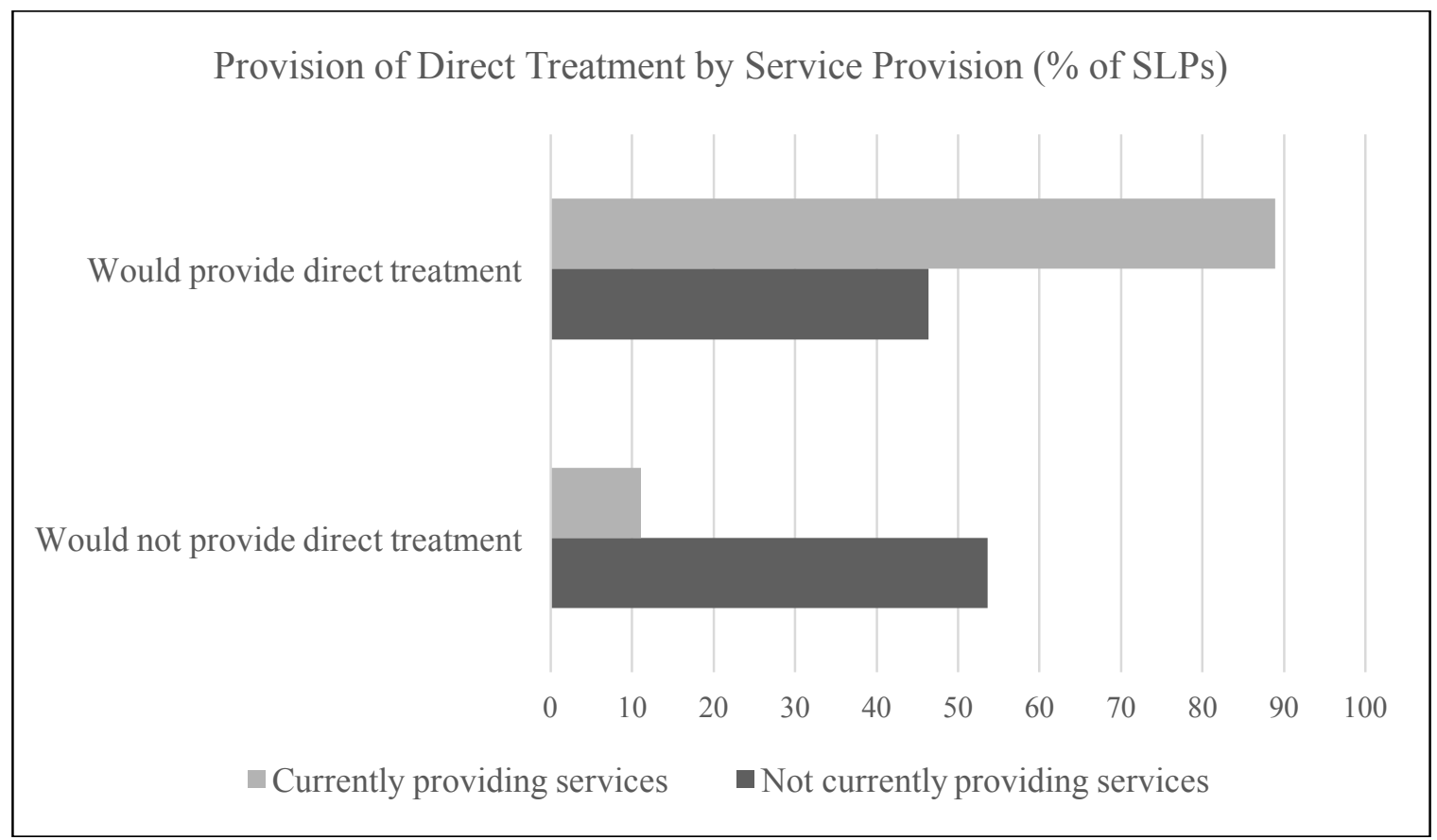

Figure 16. Provision of Direct Treatment by Service Provision (\% of SLPs) 


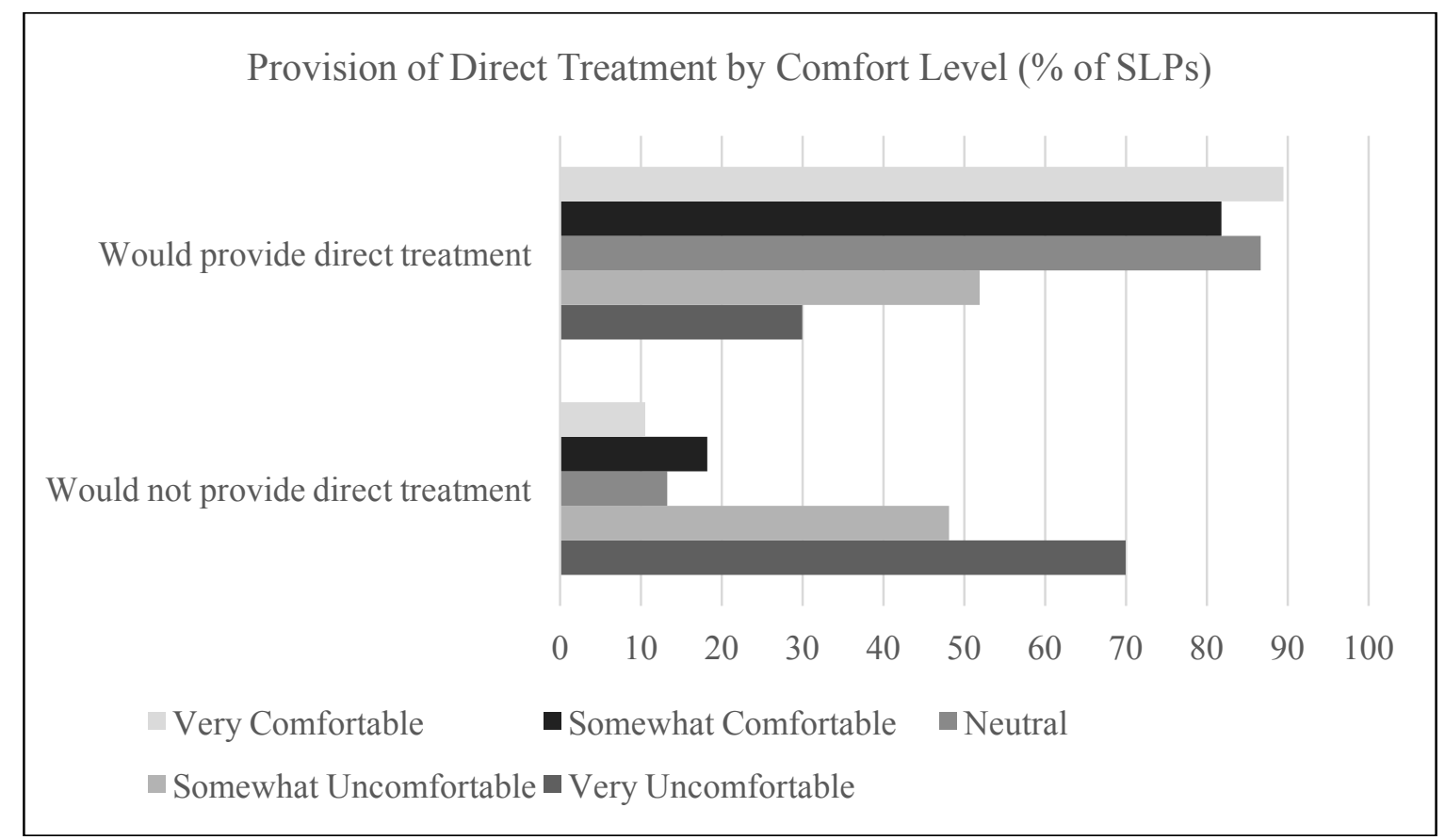

Figure 17. Provision of Direct Treatment by Comfort Level (\% of SLPs) 


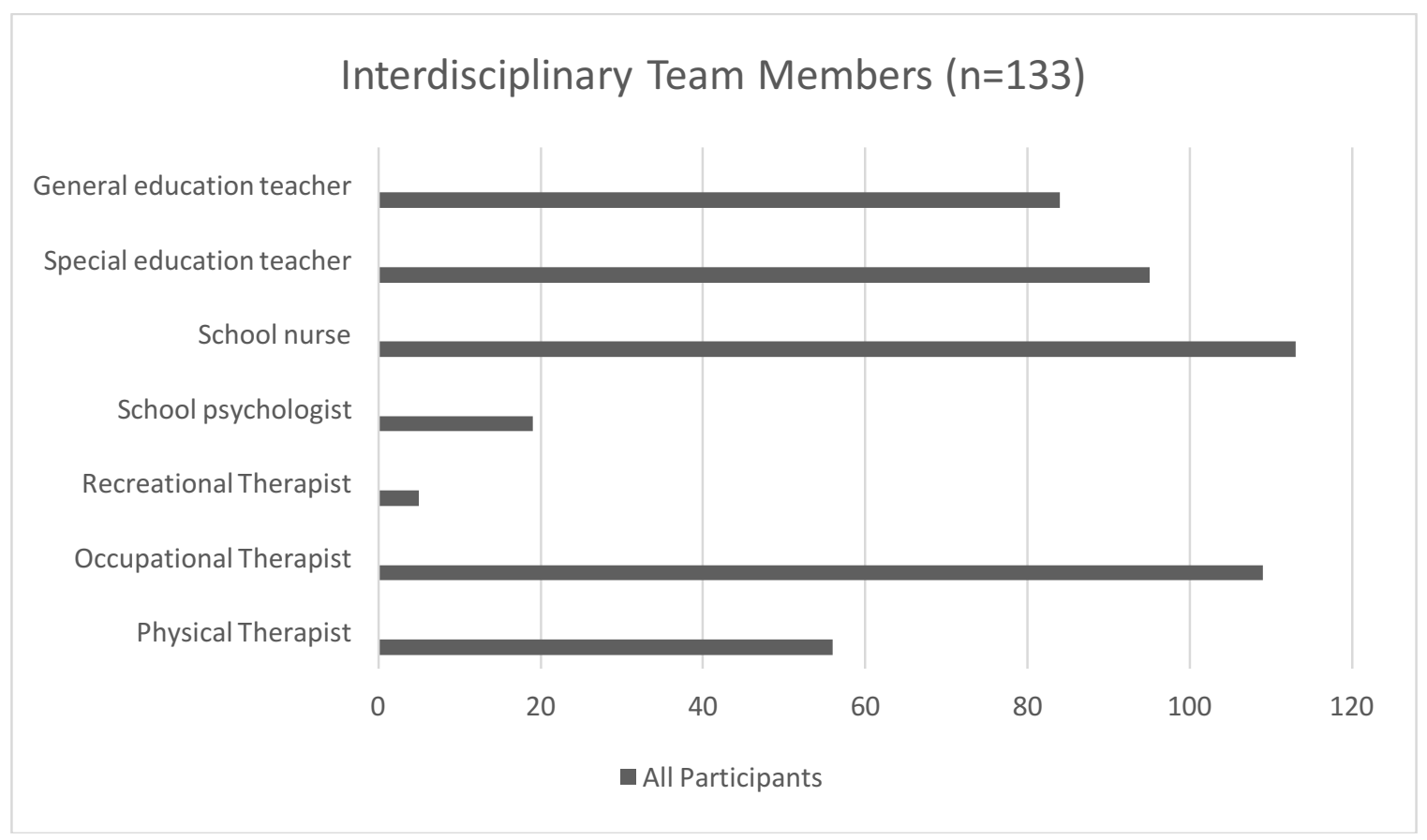

Figure 18. Interdisciplinary Team Members $(n=133)$ 


\section{STUDENTS RECEIVING OUTSIDE SERVICES}

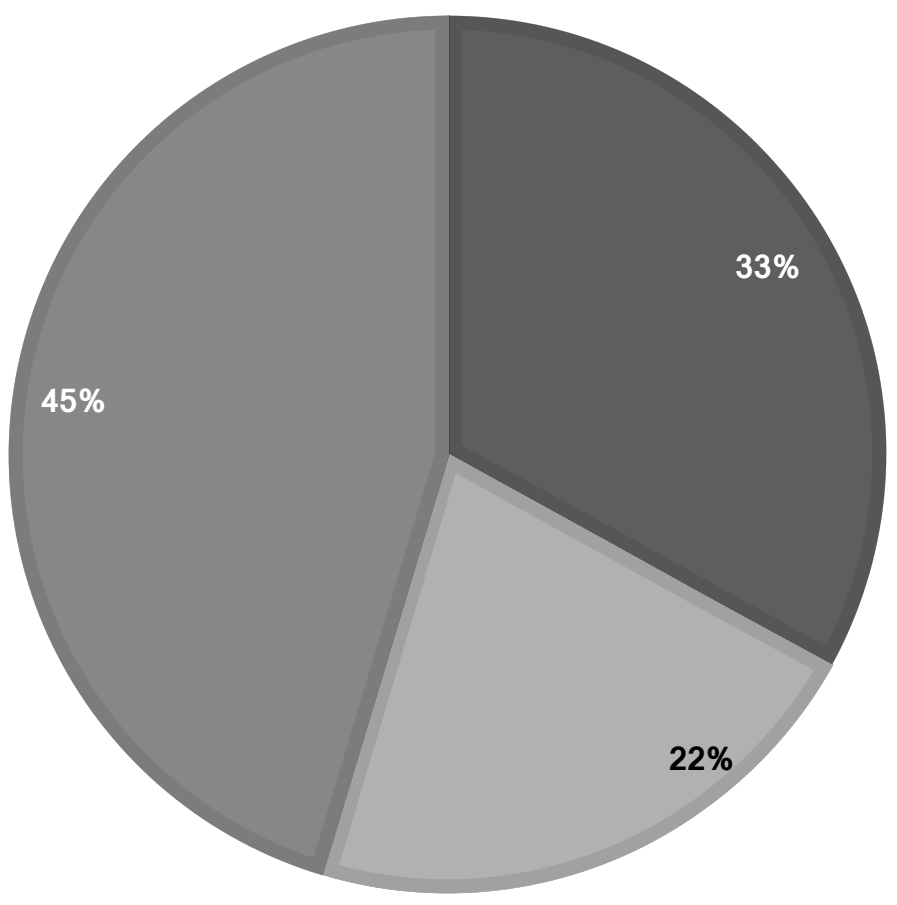

- Unknown if the students are receiving services for feeding and swallowing

Believed the students are not receiving services for feeding and swallowing

Believed the students are receiving feeding and swallowing services outside of school (e.g. outpatient clinic)

Figure 19. Students Receiving Outside Feeding and Swallowing Services 


\section{APPENDIX: SURVEY QUESTIONS}

1. Please select your title:
A. Clinical Fellow (working towards gaining ASHA certification)
B. ASHA-certified speech language pathologist
C. Other (please explain)

2. Did your graduate school curriculum cover pediatric dysphagia?
A. Yes
B. No

\section{CONDITION:}

If Yes selected: survey continues to \#3 "To what extent was pediatric dysphagia...."

If No selected: survey skips to \#4 "What state do you work in?"

3. To what extent was pediatric dysphagia covered in the curriculum?
A. Standalone pediatric dysphagia coursework
B. Pediatric dysphagia 1 credit seminar
C. Embedded within the dysphagia course ( $0-25 \%$ content $)$
D. Embedded within the dysphagia course $(25-50 \%$ content $)$
E. Other (please explain)

4. What state do you work in?

5. What type of school do you currently work at?
A. Non-charter public school
B. Charter school
C. Specialty school (e.g. special education schools)
D. Private school
E. Other (please explain)

6. What type of area do you work in?
A. Urban
B. Rural
C. Suburban
D. Other (please explain)

7. Specify the years of experience you have in each setting.

Schools:

Medical inpatient:

Medical outpatient:

Private practice:

Early intervention:

Other (please explain):

8. How many students were on your caseload in the 2017-2018 year? (Including all types of disorders) 

A. $<30$
B. $30-40$
C. $40-50$
D. $50-60$
E. $60+$

9. Do you currently provide feeding and swallowing services within your school district?
A. Yes
B. No

\section{CONDITION:}

If Yes selected survey advances to \#10a: "Please specify your years of experience..."

If No selected survey advances to \#10b: "If you were to have students with feed..."

10a. Please specify your years of experience with pediatric feeding and swallowing in the following settings.

Schools:

Medical inpatient:

Medical outpatient:

Private practice:

Early intervention:

Other (please explain):

11a. What percentage of your 2017-2018 caseload includes students with feeding and swallowing needs?
A. $<20 \%$
B. $20-40 \%$
C. $40-60 \%$
D. $>60 \%$

12a. Rate your comfort level with the following:

\begin{tabular}{|l|c|c|c|c|c|}
\hline & $\begin{array}{c}\text { Very } \\
\text { Uncomfortable }\end{array}$ & $\begin{array}{c}\text { Somewhat } \\
\text { Comfortable }\end{array}$ & Neutral & $\begin{array}{c}\text { Somewhat } \\
\text { Comfortable }\end{array}$ & Comfortable \\
\hline $\begin{array}{l}\text { Providing } \\
\text { feeding and } \\
\text { swallowing } \\
\text { therapy to a } \\
\text { client. }\end{array}$ & 0 & 0 & 0 & & \\
\hline $\begin{array}{l}\text { Providing } \\
\text { feeding and } \\
\text { swallowing } \\
\text { therapy in a } \\
\text { school } \\
\text { setting. }\end{array}$ & $\bigcirc$ & 0 & $\bigcirc$ & & \\
\hline
\end{tabular}

13a. What are the barriers to effectively providing feeding and swallowing services? (check all that apply) 
- Administrative support

$\circ$ Financial resources

- Time

- Preparedness to provide effective services

- Services would not be academically relevant

- Ethical considerations (i.e. legality of providing services in schools)

$\circ$ Other (please explain)

14a. What types of collaborative consultation do you participate in for your feeding and swallowing clients?

$\circ$ Monitoring (e.g. monitoring food prep, monitoring child's eating, etc.)

- Sharing information with interdisciplinary team members (e.g. educating other staff members, etc.)

- Other (please explain):

○ Not applicable

15a. What is your role in providing services to feeding and swallowing clients?

- Assessments

- Therapy sessions

- Other (please explain):

○ Not applicable

16a. What type of support do you receive from your district to provide these services? (check all that apply)

$\circ$ Ongoing in-house continuing education

- Financial support to attend outside continuing education

- Outside consultations

- Other (please explain):

17a. How do you supplement your professional knowledge of feeding and swallowing issues? (check all that apply)

- Attending continuing education units on feeding and swallowing

- Joining ASHA SIG 13 (groups that disseminate information on feeding and swallowing)

- Reading journals and research related to feeding and swallowing

- Participating in community forums related to feeding and swallowing

- Other (please explain):

\section{CONDITION:}

After answering question 17a: Skip to \#18 "Please read through the case study..."

10b: If you were to have students with feeding and swallowing disorders on your caseload, rate your comfort level with the following: 


\begin{tabular}{|l|c|c|c|c|c|}
\hline & $\begin{array}{c}\text { Very } \\
\text { Uncomfortable }\end{array}$ & $\begin{array}{c}\text { Somewhat } \\
\text { Comfortable }\end{array}$ & Neutral & $\begin{array}{c}\text { Somewhat } \\
\text { Comfortable }\end{array}$ & Comfortable \\
\hline $\begin{array}{l}\text { Providing } \\
\text { feeding and } \\
\text { swallowing } \\
\text { therapy to a } \\
\text { client. }\end{array}$ & 0 & & & & \\
\hline $\begin{array}{l}\text { Providing } \\
\text { feeding and } \\
\text { swallowing } \\
\text { therapy in a } \\
\text { school } \\
\text { setting. }\end{array}$ & $\bigcirc$ & 0 & $\bigcirc$ & & \\
\hline
\end{tabular}

11b: If you were to provide feeding and swallowing services, what would you see as the barriers to effectively providing feeding and swallowing services in schools? (check all that apply)
- Administrative support
- Financial resources
○ Time
- Preparedness to provide effective services
- Services would not be academically relevant
- Ethical considerations (i.e. legality of providing services in schools)
$\circ$ Other (please explain)

12b: Are there students in your district who you feel may benefit from feeding and swallowing services during the day?
A. Yes
B. No

\section{CONDITION:}

If Yes selected survey advances to \#13b: "Are these students receiving..."

If No selected survey advances to \#18: "If you were to have students with feed..."

13b: Are these students receiving feeding and swallowing services elsewhere?
A. Yes (if yes, specify where if possible)
B. No
C. Unknown

\section{CONDITION:}

After answering question 13b survey advances to \#18 "Please read through the case study..."

18. Please read through the case study in order to respond to the following questions. 
Lee is a five-year-old kindergarten student with age-appropriate cognition and expressive and receptive language skills. She presents with hypotonia as well as low gross motor function. Lee's parents report that she is often clumsy at home. Lee's teachers report that they have sent her to the nurse's office many times for falling during class time and recess.

During a clinical swallowing evaluation, it was noted that Lee has difficulty with oral containment secondary to decreased labial strength. Lee also displays an immature chewing pattern characterized by a vertical jaw movement, which results in the incomplete mastication of solids. Rotary jaw movement and lingual lateralization were noted to be absent. A recent modified barium swallow study indicated posterior bolus loss and prolonged bolus dwell times on all bolus consistencies. Penetration was observed with a positive reflexive cough response. This is consistent with the parents' reports that Lee experiences at least one coughing or choking episode during mealtime per day. After the swallow, significant bilateral pharyngeal residue was noted for pudding thick consistencies.

Explain the treatment approach you would use with this student and why you selected that approach.

Answer:

19. If oral motor exercises were part of your plan, what type of oral motor exercises would you incorporate?

Answer:

20. Identify the interdisciplinary team members who would be involved in your treatment (check all that apply):

○ Physical therapist

- Occupational therapist

- Recreational therapist

- School psychologist

- School nurse

- General education teacher

- Other (please explain):

\section{KEY:}

$\bigcirc=$ check all that apply $=$ written response

$\overline{\mathrm{A}, \mathrm{B}}, \mathrm{C}, \mathrm{D}$ etc. $=$ multiple choice

BIBLIOGRAPHY 
American Occupational Therapy Association School Mental Health Work Group (AOTA). (2013). Occupational Therapy's Role in Mental Health Promotion, Prevention, \& Intervention With Children \& Youth The Cafeteria: Creating a Positive Mealtime Experience. Retrieved from https://www.aota.org/ /media/ Corporate/Files/Practice/Children/Cafeteria-Mealtime-Info-Sheet.pdf

American Speech-Language-Hearing Association (ASHA). (2007, Rescinded: 2014). Guidelines for Speech-Language Pathologists Providing Swallowing and Feeding Services in Schools [Guidelines]. Retrieved from https:/www.asha.org/ policy/GL200 7-00276/

American Speech-Language-Hearing Association (ASHA). (2016). Scope of practice in speech-language pathology. Retrieved from https://www.asha.org/policy/sp2016$00343 /$

American Speech-Language-Hearing Association (ASHA). (2016). Code of ethics. Retrieved from www.asha.org/policy/.

American Speech-Language-Hearing Association (ASHA). (2017). 2017 SLP health care survey summary report: Number and type of responses. Retrieved from https:// www.asha.org/uploadedFiles/2017-SLP-Health-Care-Survey-Summary.pdf American Speech-Language-Hearing Association (ASHA) (2018). Employment Settings for SLPs. Retrieved from https://www.asha.org/students/employment-settings-forslps/.

American Speech-Language-Hearing Association (ASHA). (2018). 2018 Schools survey. 
Survey summary report: Numbers and types of responses, SLPS. Retrieved from https://www.asha.org/research/memberdata/schoolssurvey.

American Speech-Language-Hearing Association (ASHA). (2019). Caseload and

Workloads. Retrieved from https://www.asha.org/PRPSpecificTopic.asp x?folderid=85899 34681\&section=Overview

Angell, M. E., Bailey, R. L., Nicholson, J. K., \& Stoner, J. B. (2009). Family involvement in school-based dysphagia management. Physical Disabilities: Education and Related Services, 28(1), 6-24.

Arvedson, J. C. (2008). Assessment of pediatric dysphagia and feeding disorders: Clinical and instrumental approaches. Developmental Disabilities Research Reviews, 14, 118-127.

Arvedson, J. C., \& Homer, E. M. (2006). Managing dysphagia in the schools. The ASHA Leader, 11(13), 8-9.

Bailey, R. L., \& Angell, M. E. (2008). The ABCs of dysphagia management in schools: An overview of practical strategies. The ASHA Leader, 13(1), 8-11.

Bailey, R. L., Stoner, J. B., Angell, M. E., \& Fetzer, A. (2008). School-based speechlanguage pathologists' perspectives on dysphagia management in the schools. Language, Speech, and Hearing Services in Schools, 39, 441-450.

Benton School District, 113 LRP 17149, SEA AR 2012.

Bhattacharyya, N. (2015). The prevalence of pediatric voice and swallowing problems in the United States. The Laryngoscope, 125, 746-750.

Carnaby, G. D., \& Harenberg, L. (2013). What is "usual care" in dysphagia 
rehabilitation: A survey of USA dysphagia practice patterns. Dysphagia, 28(4), $567-574$.

Connecticut Department of Education (Connecticut DOE). (2008). Guidelines for Feeding and Swallowing Programs in Schools.

Contoocock Valley School District, 41 IDELR 45, SEA NH 2004.

Delaney, A. L., \& Arvedson, J. C. (2008). Development of swallowing and feeding: prenatal through first year of life. Developmental Disabilities Research Reviews, 14(2), 105-117.

Durlak, J. A., Weissberg, R. P., Dymnicki, A. B., Taylor, R. D., \& Schellinger, K. B. (2011). The impact of enhancing students' social and emotional learning: A metaanalysis of school-based universal interventions. Child Development, 82(1), 405432.

Excel. Version: 15.27 (2016). Microsoft Windows. Redmond, WA, USA.

Goyal, R. K., \& Mashimo, H. (2006). Physiology of oral, pharyngeal, and esophageal motility. Springer Nature GI Motility Online.

Heyne, L., Wilkins, V., \& Anderson, L. (2012). Social inclusion in the lunchroom and on the playground at school. Social Advocacy and Systems Change Journal, 3, 5468.

Homer, E. M., Bickerton, C., Hill, S., Parham, L., \& Taylor, D. (2000). Development of an interdisciplinary dysphagia team in the public schools. Language, Speech, and Hearing Services in Schools, 31(1), 62-75.

Homer, E. M. (2008). Establishing a public school dysphagia program: A model for 
administration and service provision. Language, Speech, and Hearing Services in Schools, 39, 177-191.

Homer, E. M. (2003). An interdisciplinary team approach to providing dysphagia treatment in the schools. Seminars in Speech and Language, 24(03), 215-234.

Homer, E. M. (2015). Management of Swallowing and Feeding Disorders in Schools. San Diego, CA. Plural Publishing.

Hutchins, T. L., Gerety, K. W., \& Mulligan, M. (2011). Dysphagia Management: A survey of school-based speech-language pathologists in Vermont. Language Speech and Hearing Services in Schools, 42(2), 194-206.

Kauffman, J. M., Hallahan, D. P., \& Pullen, P. C. (2017). Handbook of Special Education. New York, NY. Routledge.

Kelly, B. N., Huckabee, M. L., Jones, R. D., \& Frampton, C. M. (2007). The first year of human life: coordinating respiration and nutritive swallowing. Dysphagia, 22(1), $37-43$.

Lefton-Greif, M. A., \& Arvedson, J. C. (2008). Schoolchildren with dysphagia associated with medically complex conditions. Language, Speech, and Hearing Services in Schools, 39, 237-248.

Le Révérend, B. J., Edelson, L. R., \& Loret, C. (2014). Anatomical, functional, physiological and behavioural aspects of the development of mastication in early childhood. British Journal of Nutrition, 111(3), 403-414.

Loughlin, G. M. (1989). Respiratory consequences of dysfunctional swallowing and aspiration. Dysphagia, 3(3), 126-130.

Manikam, R. (2000). Current Literature: Pediatric Feeding Disorders. Nutrition in 
Clinical Practice, 15(6), 312-314.

Matsuo, K., \& Palmer, J. B. (2008). Anatomy and physiology of feeding and swallowing: normal and abnormal. Physical Medicine and Rehabilitation Clinics of North America, 19(4), 691-707.

McNeilly, L. G., \& Sheppard, J. J. (2008). Managing dysphagia in the schools. Language, Speech, and Hearing Services in Schools, 39, 273-274.

Miller, C. K. (2009). Optimizing collaboration between medical and school-based speech-language pathologists managing pediatric dysphagia. Perspectives on Swallowing and Swallowing Disorders (Dysphagia), 18(3), 91-96.

Morgan, A. T., Dodrill, P., \& Ward, E. C. (2012). Interventions for oropharyngeal dysphagia in children with neurological impairment. Cochrane Database of Systematic Reviews, (10).

Morris, S. E., \& Klein, M. D. (2000). Pre-Feeding Skills: A comprehensive resource for mealtime development. Dallas, TX: Pro Ed.

New Mexico Department of Education 103 LRP, 57798, SEA NM 2003.

NVivo for Windows: NVivo Qualitative Data Analysis Software; QSR International Party Ltd. Version 10, 2014.

O’Donoghue, C. R., \& Dean-Claytor, A. (2008). Training and self-reported confidence for dysphagia management among speech-language pathologists in the schools. Language Speech and Hearing Services in Schools, 39(2), 192-198.

O'Donoghue, C. R., \& Hegyi, S. E. (2009). Dysphagia management in the schools: 
Concepts in training and competency. Perspectives on Swallowing and Swallowing Disorders (Dysphagia), 18(3), 103-108.

Owre, D. W. (2001). Commentary: A "real world" focus on dysphagia intervention in the schools. Perspectives on Swallowing and Swallowing Disorders (Dysphagia), 10(2), 13-15.

Power-deFur, L., \& Alley, N. S. (2008). Legal and financial issues associated with providing services in schools to children with swallowing and feeding disorders. Language, Speech, and Hearing Services in Schools. 39(2), 160-166.

Qualtrics. (2013). Qualtrics XM. Provo, UT, USA.

Sharp, W. G., Berry, R. C., McCracker, C., Nuhu, N. N., Marvel, E., Saulnier, C.A., \& Jacques, D. C. (2013). Feeding problems and nutrient intake in children with autism disorders: A meta-analysis and comprehensive review of the literature. Journal of Autism and Developmental Disorders, 43, 2159-2173.

SPSStatistics. Version 25. (2017). IBM Software. Armonk, New York.

Stevenson, R. D., \& Allaire, J. H. (1991). The development of normal feeding and swallowing. Pediatric Clinics of North America, 38(6), 1439-1453.

Virginia Department of Education (VDOE). (2018). Speech-language pathology services in schools: Guidelines for best practice. 